OPEN ACCESS

Edited by:

Petra Patakova,

University of Chemistry

and Technology in Prague, Czechia

Reviewed by:

Qiuqiang Gao,

Columbia University, United States

Jingyu Wang,

Westlake Institute for Advanced

Study, China

Yi Wang,

Auburn University, United States

*Correspondence:

Thaddeus Chukwuemeka Ezeji ezeji.1@osu.edu

Venkat Gopalan

gopalan.5@osu.edu

Specialty section:

This article was submitted to

Synthetic Biology,

a section of the journal

Frontiers in Bioengineering and

Biotechnology

Received: 18 February 2021 Accepted: 04 May 2021

Published: 08 June 2021

Citation:

Ujor VC, Lai LB, Okonkwo CC, Gopalan V and Ezeji TC (2021)

Ribozyme-Mediated Downregulation Uncovers DNA Integrity Scanning Protein A (DisA) as a Solventogenesis Determinant in Clostridium beijerinckii. Front. Bioeng. Biotechnol. 9:669462. doi: 10.3389/fbioe.2021.669462

\section{Ribozyme-Mediated Downregulation Uncovers DNA Integrity Scanning Protein A (DisA) as a Solventogenesis Determinant in Clostridium beijerinckii}

\author{
Victor Chinomso Ujor ${ }^{1}$, Lien B. Lai ${ }^{2}$, Christopher Chukwudi Okonkwo ${ }^{3}$, \\ Venkat Gopalan $^{2 *}$ and Thaddeus Chukwuemeka Ezeji ${ }^{* *}$
}

${ }^{1}$ Fermentation Science Program, Department of Food Science, University of Wisconsin-Madison, Madison WI,
United States, ${ }^{2}$ Department of Chemistry and Biochemistry, Center for RNA Biology, The Ohio State University, Columbus,
OH, United States, ${ }^{3}$ Department of Animal Sciences, Ohio State Agricultural Research and Development Center, The Ohio State University, Wooster, $\mathrm{OH}$, United States

Carbon catabolite repression (CCR) limits microbial utilization of lignocellulosederived pentoses. To relieve CCR in Clostridium beijerinckii NCIMB 8052, we sought to downregulate catabolite control protein A (CcpA) using the M1GS ribozyme technology. A CcpA-specific ribozyme was constructed by tethering the catalytic subunit of Escherichia coli RNase P (M1 RNA) to a guide sequence (GS) targeting CcpA mRNA (M1GSCcpA). As negative controls, the ribozyme M1GSCcpA-Sc (constructed with a scrambled $\mathrm{GS}^{\mathrm{CcPA}}$ ) or the empty plasmid pMTL500E were used. With a 3-fold knockdown of CcpA mRNA in C. beijerinckil expressing M1GSCcpA (C. beijerinckii_M1GS ${ }^{\mathrm{C} p \mathrm{~A}}$ ) relative to both controls, a modest enhancement in mixed-sugar utilization and solvent production was achieved. Unexpectedly, C. beijerinckii_M1GSCcpA-Sc produced 50\% more solvent than C. beijerinckii_pMTL500E grown on glucose + arabinose. Sequence complementarity (albeit suboptimal) suggested that M1GSCcpA-Sc could target the mRNA encoding DNA integrity scanning protein $A$ (DisA), an expectation that was confirmed by a 53-fold knockdown in DisA mRNA levels. Therefore, M1GSCcpA-Sc was renamed M1GSDisA. Compared to C. beijerinckii_M1GSCcpA and_pMTL500E, C. beijerinckii_M1GS ${ }^{\text {DisA }}$ exhibited a 7 -fold decrease in the intracellular c-di-AMP level after $24 \mathrm{~h}$ of growth and a near-complete loss of viability upon exposure to DNA-damaging antibiotics. Alterations in c-di-AMP-mediated signaling and cell cycling likely culminate in a sporulation delay and the solvent production gains observed in C. beijerinckii_M1GS ${ }^{\text {DisA }}$. Successful knockdown of the CcpA and DisA mRNAs demonstrate the feasibility of using M1GS technology as a metabolic engineering tool for increasing butanol production in C. beijerinckii.

Keywords: butanol, carbon catabolite repression, M1GS, solventogenesis, metabolic engineering, Clostridium beijerinckii, RNase $\mathrm{P}$ 


\section{INTRODUCTION}

The ability of solventogenic Clostridium species to utilize a wide range of sugar substrates to produce acetone, butanol, and ethanol (ABE) makes them suitable candidates for generating transport fuels and chemical feedstocks from renewable biomaterials (Jones and Woods, 1986; Grupe and Gottschalk, 1992; Ezeji et al., 2010). Among solvents produced by these Gram-positive, obligately anaerobic, spore-forming bacteria, butanol has drawn the most attention. Owing to its physicochemical properties, butanol is an ideal transport fuel and has numerous applications in food, plastic, and rubber industries (Ezeji et al., 2003, 2010). However, bio-butanol production is currently economically unviable due to the high cost of substrates, low productivity, and low yield (Ezeji et al., 2007).

Lignocellulose, the most plentiful renewable resource for production of fermentable sugars, has been explored as an inexpensive substrate (Ho et al., 1998; Ezeji et al., 2007; Ren et al., 2010). Hydrolysis of lignocellulose releases mainly glucose and xylose with small amounts of other sugars including arabinose and mannose (Ho et al., 1998; Zverlov et al., 2006; Ezeji et al., 2007). Depending on the source, lignocellulosic biomass hydrolysates (LBH) can contain up to $58 \%$ glucose and $36 \%$ pentose (xylose + arabinose). While clostridia can utilize all these sugars, pentose utilization is drastically limited in the presence of glucose, an attribute that hampers solvent yield and productivity from LBH (Ounine et al., 1985; Mitchell, 1998; Ren et al., 2010). Thus, overriding this hierarchy in sugar utilization, a phenomenon named carbon catabolite repression (CCR), has been an important research objective in this field.

CCR is globally mediated by catabolite control protein A (CcpA), which in the presence of glucose represses the expression of numerous genes involved in the utilization of non-glucose substrates (Ludwig et al., 2002; Singh et al., 2008; Ren et al., 2010). Indeed, CcpA knockout in Clostridium acetobutylicum ATCC 824 led to concomitant utilization of glucose and xylose (Ren et al., 2010). However, compared to the wild type, this knockout strain was (i) less stable, (ii) produced less ABE and more acids (likely due to poor acid re-assimilation), and (iii) exhibited impaired sporulation (Ren et al., 2010, 2012). Such a broad range of effects was perhaps to be expected since CcpA, besides regulating carbon metabolism, exerts a pleiotropic effect on the expression of diverse genes unrelated to carbon utilization in C. acetobutylicum (Ren et al., 2012), Bacillus subtilis (Ludwig et al., 2002), Enterococcus faecalis (Leboeuf et al., 2000), and Lactobacillus plantarum (Mazzeo et al., 2012). In C. acetobutylicum, global transcriptomic analysis of the CcpA-null mutant relative to the wild type revealed that CcpA upregulates key solventogenic and sporulation genes, while negatively influencing the expression of acidogenic genes (Ren et al., 2012). Given the multiple roles of CcpA, we reasoned that a knockdown strain with some residual function would relieve CCR without engendering all the negative effects observed with the CcpA knockout. We therefore explored a ribozyme (RNase P)-mediated approach to knock down CcpA mRNA in C. beijerinckii NCIMB 8052.
In all domains of life, the primary function of RNase $\mathrm{P}$ is to remove the $5^{\prime}$ leader from precursor tRNAs (pre-tRNAs; Scott and Engelke, 2006; Altman, 2007; Lai et al., 2010). The ribonucleoprotein (RNP) form of bacterial RNase P comprises a catalytic RNA subunit (termed M1 RNA in Escherichia coli) and one protein cofactor. Any cellular RNA could be targeted for cleavage by RNase P (Forster and Altman, 1990; GuerrierTakada and Altman, 2000) if the binding of the target RNA to a guide sequence (GS) forms a sequence- and structure-specific complex resembling the acceptor-T-stem helical stack in the pretRNA, a key recognition determinant of RNase P. The design also includes an (A/G)CCA sequence at the $3^{\prime}$ end of the GS to mimic the $3^{\prime}$ end of pre-tRNAs. An important variation that enhanced the efficiency of this method is the covalent tethering of M1 RNA to the GS (Li and Altman, 1996; Liu, 2010). When the GS in such an engineered M1GS binds an accessible, single-stranded region in its target RNA to form a stem substrate, the bipartite substrate is cleaved in cis by the covalently attached M1 RNA (Figure 1A). Scrambling the GS while retaining the nucleotide composition provides a control to assess specificity of targeting. Given the proven utility of this method for targeted degradation of RNAs in bacteria, mammalian cells, and mice (Li and Altman, 1996; Bai et al., 2010, 2011; Liu, 2010), we sought its application for knocking down CcpA in C. beijerinckii.

While expression of a customized CcpA-specific M1 RNAbased ribozyme (M1GS ${ }^{\mathrm{CcpA}}$ ) in C. beijerinckii displayed a 3fold knockdown in the CcpA mRNA level and a small but discernible increase in ABE production, we unexpectedly found that the specificity control M1GS with a scrambled GS $S^{\mathrm{CcpA}}$ resulted in a 1.5-fold increase in ABE titer compared to a strain transformed with the empty vector. Upon further investigation, we found that the scrambled GS ${ }^{\mathrm{CcpA}}$ targeted the mRNA encoding DNA integrity scanning protein A (DisA) and caused a 53-fold decrease in the DisA mRNA steadystate level. DisA monitors genomic integrity at the onset of sporulation and recruits the DNA repair machinery upon detection of DNA damage (Oppenheimer-Shaanan et al., 2011). While DisA scans the genomic DNA, it produces cyclic diadenosine monophosphate (c-di-AMP), a second messenger critical for cellular homeostasis (Stülke and Krüger, 2020). In fact, c-di-AMP activates Spo0A, a master transcriptional regulator of sporulation. Thus, M1GS ${ }^{\text {DisA }}$-mediated knockdown of DisA might enhance solventogenesis by delaying sporulation. In addition to uncovering this unanticipated nexus between DisA, c-di-AMP, and ABE production, our work demonstrates the utility of the M1GS technology as a tool for metabolic engineering of $C$. beijerinckii and likely other solventogenic Clostridium species.

\section{MATERIALS AND METHODS}

\section{M1GS Design and Cloning}

Translational initiation requires binding of the ribosome to a single-stranded region near the start codon. Therefore, we used the mfold web server (Zuker, 2003), which predicts RNA secondary structures based on energy minimization, to 
A

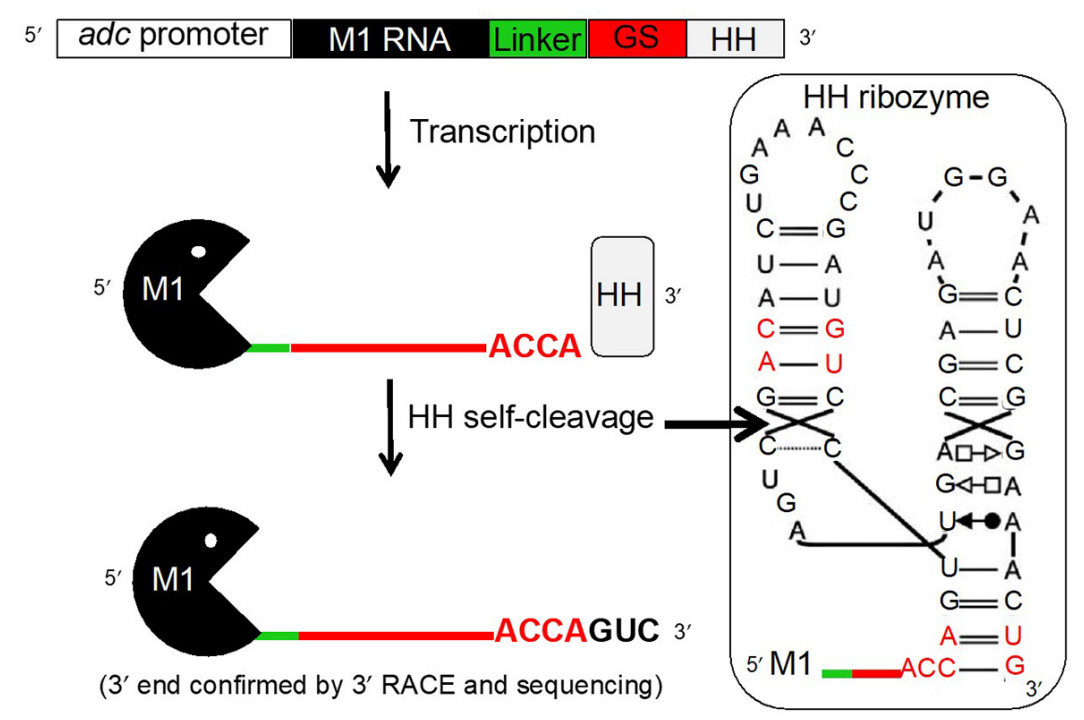

B

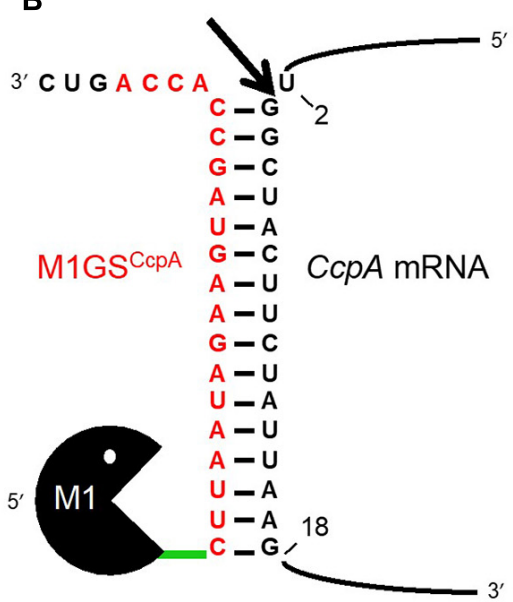

C

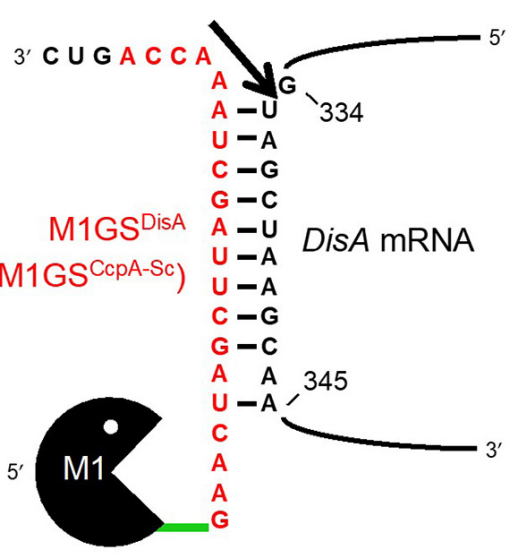

D

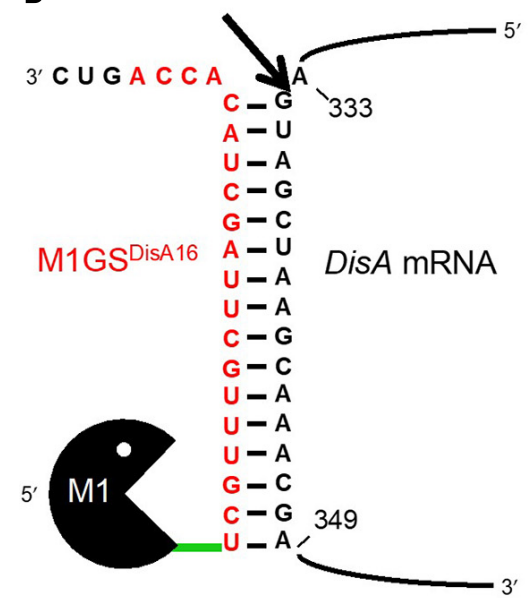

FIGURE 1 | The M1GS approach. (A) The M1GS construct was transcriptionally controlled by the C. acetobutylicum adc promoter. A 51-nucleotide linker between M1 RNA and the GS was engineered to allow flexibility between them. After transcription, the hammerhead $(\mathrm{HH})$ ribozyme self-cleaved with high efficiency at the precise location indicated by the arrow in the inset, leaving the M1GS transcripts with only three additional $3^{\prime}$ nucleotides. The inset shows the M1GS transcript with the full secondary structure of the $\mathrm{HH}$ ribozyme; the red-colored nucleotides are those that were modified to facilitate cloning and to minimize the number of additional bases at the $3^{\prime}$ ends of M1GS. Annealing of M1GSCcpA $(B), M 1 G S^{D i s A}$ (C), and M1GS DisA16 (D) to their respective target mRNAs. The numbers indicate the nucleotide positions targeted by the ribozymes in the mRNAs (with AUG numbering 1-3). The arrows indicate where the tethered M1 RNA is expected to cleave the mRNAs.

determine single-strandedness in nucleotides -25 to +55 of the CcpA open reading frame (ORF). Such an analysis led us to design $\mathrm{GS}^{\mathrm{CcpA}}$ for targeting nucleotides 3-18 of the CcpA ORF (Figure 1B). The scrambled version GSCcpA-Sc, which was originally intended as a negative control for $\mathrm{GS}^{\mathrm{CcpA}}$, was subsequently discovered to fortuitously target nucleotides 335343 of the DisA ORF (Figure 1C). These sequences including the $3^{\prime}$ ACCA were inserted between the linker and the hammerhead $(\mathrm{HH})$ ribozyme sequences in pBT7-M1-HH, a template vector that harbored sequences for M1 RNA, a 51-nucleotide linker, and a $\mathrm{HH}$ ribozyme in tandem (Figure 1A) and downstream of the T7 RNA polymerase promoter. Using inverse PCR and back-to-back primers (Table 1) flanking the linker-HH border
[GS/HH-F and a reverse primer that includes the GS sequence: GS(CcpA)-R or GS(CcpA-Sc)-R], the entire pBT7-M1GS-HH plasmid was amplified, circularized by ligation, and used to transform E. coli DH5 $\alpha$ cells. Subsequently, primers 5'M1(ApaI)$\mathrm{F}$ and $3^{\prime} \mathrm{HH}(X h o \mathrm{I})-\mathrm{R}$ were used to introduce an $A p a \mathrm{I}$ and a XhoI site by PCR just upstream of M1 RNA and downstream of $\mathrm{HH}$, respectively, using $\mathrm{pBT} 7-\mathrm{M} 1 \mathrm{GS}-\mathrm{HH}$ as the template. After digestion with ApaI and XhoI, the PCR products were cloned into pWUR459 (under the control of an inducible adc promoter; Siemerink et al., 2011) that had been digested with the same restriction enzymes.

Since only nine contiguous nucleotides in DisA ORF were complementary to M1GS ${ }^{\text {DisA }}$ (Figure 1C), we constructed 
TABLE 1 | Sequences of oligonucleotides used in this study.

\begin{tabular}{|c|c|c|}
\hline Primer Name & Target gene/template & Sequence $\left(5^{\prime} \rightarrow 3^{\prime}\right)$ \\
\hline $\mathrm{GS} / \mathrm{HH}-\mathrm{F}$ & M1GS & $\begin{array}{l}\text { ACCAGTCGACA } \\
\text { TCTGAAACCC }\end{array}$ \\
\hline $\mathrm{GS}(\mathrm{CcpA})-\mathrm{R}$ & M1GS ${ }^{\mathrm{Ccp} A}$ & $\begin{array}{l}\text { GGCTACTTCTATT } \\
\text { AAGAAACCTATG } \\
\text { ACCATGATTA }\end{array}$ \\
\hline $\mathrm{GS}(\mathrm{Ccp} A-\mathrm{Sc})-\mathrm{R}$ & M1GS DisA & $\begin{array}{l}\text { TTAGCTAAGCTAGT } \\
\text { TCAAACCTATGA } \\
\text { CCATGATTA }\end{array}$ \\
\hline 5'M1(Apal)-F & M1GS & $\begin{array}{l}\text { CATGGGCCC } \\
\text { GAAGCTGACCAGAC }\end{array}$ \\
\hline 3'HH(Xhol)-R & M1GS & $\begin{array}{l}\text { CGTGCTCGAGG } \\
\text { TGAAACTGACC }\end{array}$ \\
\hline M1-F & E. coli M1 RNA & $\begin{array}{l}\text { GACCAGTGC } \\
\text { AACAGAGAGC }\end{array}$ \\
\hline M1-R & E. coli M1 RNA & $\begin{array}{l}\text { GTCGTGGACA } \\
\text { GTCATTCATC }\end{array}$ \\
\hline Cbei_R0124-F & C. beijerinckii 16S rRNA & $\begin{array}{l}\text { GAAGAATACCAG } \\
\text { TGGCGAAGGC }\end{array}$ \\
\hline Cbei_R0124-R & C. beijerinckii 16S rRNA & $\begin{array}{l}\text { ATTCATCGTT } \\
\text { TACGGCGTGGAC }\end{array}$ \\
\hline Cbei_0047-F & C. beijerinckii CcpA & $\begin{array}{l}\text { GTTGCAAAAG } \\
\text { AAGCAGGAG }\end{array}$ \\
\hline Cbei_0047-R & C. beijerinckii CcpA & $\begin{array}{l}\text { CAGCACCTCT } \\
\text { TACAATITCTG }\end{array}$ \\
\hline Cbei_0127-F & C. beijerinckii DisA & $\begin{array}{l}\text { GAAACAGGAAC } \\
\text { TAGGCATAGAAC }\end{array}$ \\
\hline Cbei_0127-R & C. beijerinckii DisA & $\begin{array}{l}\text { CTTGATTGGCCT } \\
\text { TTCCAAG }\end{array}$ \\
\hline M1p3-F (delta-M1GS) & C. beijerinckii DisA-16 & $\begin{array}{l}\text { GCTTCGTCGTC } \\
\text { GTCCTCTTCG }\end{array}$ \\
\hline M1p12-R (delta-M1GS) & C. beijerinckii DisA-16 & $\begin{array}{l}\text { CCATCGGCGG } \\
\text { TाTGCTCTCTG }\end{array}$ \\
\hline F-ext & pBT7 vector & $\begin{array}{l}\text { CGACGTTGTAAAA } \\
\text { CGACGGCCAG }\end{array}$ \\
\hline M1GS-3F & M1GS & $\begin{array}{l}\text { GAAGCTGACCA } \\
\text { GACAGTCGC }\end{array}$ \\
\hline M1-4F & M1GS & $\begin{array}{l}\text { AGGGTGCCA } \\
\text { GGTAACGCC }\end{array}$ \\
\hline
\end{tabular}

M1GS ${ }^{\text {DisA } 16}$ that targets 16 nucleotides (334-349) in DisA ORF (Figure 1D). For use as a negative control, we generated $\Delta \mathrm{M} 1 \mathrm{GS} \mathrm{S}^{\mathrm{Dis} A 16}$ where an M1 RNA deletion mutant $(\Delta \mathrm{M} 1)$ substituted for the wild type such a control provides an opportunity to assess gene expression changes arising solely from antisense effects (Liu and Altman, 1995; Gopalan et al., 2002). All the cloned inserts were verified by sequencing before using to transform C. beijerinckii.

\section{Strains and Culture Conditions}

Clostridium beijerinckii NCIMB 8052 was obtained from the American Type Culture Collection (Manassas, VA, United States) as C. beijerinckii ATCC 51743 (the same strain is labeled differently as NCIMB 8052 by the NCIMB culture collection, United Kingdom). Laboratory stocks were maintained as spore suspensions in sterile, double-distilled water at $4^{\circ} \mathrm{C}$. All cultures were grown at $35 \pm 1^{\circ} \mathrm{C}$ in tryptone-glucose-yeast extract (TGY; 30,20 , and $10 \mathrm{~g} / \mathrm{L}$, respectively) broth, and in an anaerobic chamber (Coy Laboratory Products Inc., Grass Lake, MI, United States) with a modified atmosphere of $82 \% \mathrm{~N}_{2}, 15 \% \mathrm{CO}_{2}$, and $3 \% \mathrm{H}_{2}$.

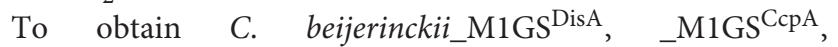
${ }_{\text {_M1GS }}{ }^{\text {DisA 16 }}, \Delta$ M1GS ${ }^{\text {DisA 16 }}$, and _pMTL500E, transformation of $C$. beijerinckii with the corresponding M1GS constructs or the parental plasmid pMTL500E was conducted as described by Kim and Blaschek (1993) with minor modifications. First, a starter culture was grown for $12 \mathrm{~h}$ before sub-culturing [10\% (v/v) inoculum] into fresh TGY broth and grown until late-exponential phase $\left(\mathrm{OD}_{600} \sim 1.2\right)$. For each transformation, $10 \mathrm{~mL}$ of cells were harvested, washed with electroporation solution [10\% (w/v) polyethylene glycol 8000 in distilled water], and re-suspended in $1 \mathrm{~mL}$ of the same solution. Four hundred $\mu \mathrm{l}$ of this suspension was then mixed with $10 \mu \mathrm{g}$ of plasmid DNA and subjected to electroporation at $2.5 \mathrm{kV}, 25 \mu \mathrm{F}$, and infinite resistance in a Gene Pulser (Bio-Rad, Hercules, CA, United States). Subsequently, cells were quickly transferred to $5 \mathrm{~mL}$ of TGY broth and grown for $8 \mathrm{~h}$, before being plated on TGY agar $[0.45 \%(\mathrm{w} / \mathrm{v})$ agar] containing erythromycin $(25 \mu \mathrm{g} / \mathrm{mL})$ and incubated overnight at $35 \pm 1^{\circ} \mathrm{C}$. Single colonies were then suspended in $500 \mu \mathrm{l}$ of TGY, re-streaked on TGY agar (+25 $\mu \mathrm{g} / \mathrm{mL}$ erythromycin), and incubated overnight at $35 \pm 1^{\circ} \mathrm{C}$. Fresh colonies were then picked and grown in TGY broth for $12 \mathrm{~h}$ to make a glycerol stock. In parallel, cells were sub-cultured into P2 medium containing $60 \mathrm{~g} / \mathrm{L}$ glucose (+25 $\mu \mathrm{g} / \mathrm{mL}$ erythromycin) and grown for 7 days to generate spores for subsequent experiments. The P2 medium $(100 \mathrm{~mL})$ used for fermentative characterization of the strains contained $60 \mathrm{~g} / \mathrm{L}$ glucose, arabinose or xylose, or glucose-pentose mixtures totaling $60 \mathrm{~g} / \mathrm{L}$ sugars $[40 \mathrm{~g} / \mathrm{L}$ glucose and $20 \mathrm{~g} / \mathrm{L}$ pentose (arabinose or xylose)] and $1 \mathrm{~g} / \mathrm{L}$ yeast extract supplemented with $1 \mathrm{~mL}$ each of buffer, vitamin, and mineral stocks. The buffer stock contained $\mathrm{K}_{2} \mathrm{HPO}_{4}(50 \mathrm{~g} / \mathrm{L})$ and ammonium acetate $(220 \mathrm{~g} / \mathrm{L})$, while the vitamin stock contained $p$-amino-benzoic acid $(0.1 \mathrm{~g} / \mathrm{L})$, thiamine $(0.1 \mathrm{~g} / \mathrm{L})$, and biotin $(0.001 \mathrm{~g} / \mathrm{L})$. The mineral stock comprised $\mathrm{MgSO}_{4} \cdot 7 \mathrm{H}_{2} \mathrm{O}(20 \mathrm{~g} / \mathrm{L}) \mathrm{MnSO}_{4} \cdot \mathrm{H}_{2} \mathrm{O}$ $(1 \mathrm{~g} / \mathrm{L}), \mathrm{FeSO}_{4} \cdot 7 \mathrm{H}_{2} \mathrm{O}(1 \mathrm{~g} / \mathrm{L})$, and $\mathrm{NaCl}(1 \mathrm{~g} / \mathrm{L})$.

For fermentation, all cultures were grown in loosely capped 250-mL Pyrex culture bottles at $35 \pm 1^{\circ} \mathrm{C}$. For phenotypic characterization of $C$. beijerinckii_M1GS ${ }^{\text {DisA }}$,

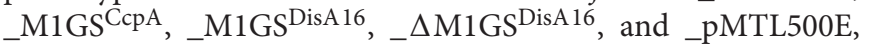
inoculum generation and fermentation were conducted as described above (also see Ujor et al., 2014). Cultures for the determination of intracellular c-di-AMP levels were grown in the glucose + arabinose medium for $60 \mathrm{~h}$ with aliquots withdrawn every $12 \mathrm{~h}$ starting at $0 \mathrm{~h}$. In addition to the standard potassium phosphate buffer $\left(\mathrm{K}_{2} \mathrm{HPO}_{4}, 0.5 \mathrm{~g} / \mathrm{L}\right.$ final concentration), all fermentation media were buffered with 2-(N-morpholino) ethanesulfonic acid (MES; $7 \mathrm{~g} / \mathrm{L}$ ) and supplemented with erythromycin $(25 \mu \mathrm{g} / \mathrm{mL})$.

\section{RNA Isolation and RT-Quantitative PCR (RT-qPCR)}

Cell pellets from $6 \mathrm{~mL}$ of culture grown in glucose + arabinose medium for $24 \mathrm{~h}$ were used for RNA isolation. RNA was isolated individually from triplicate cultures of $C$. beijerinckii strains 


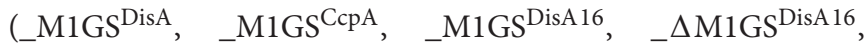
or _pMTL500E). Each cell pellet was suspended in $1 \mathrm{~mL}$ of TRI Reagent (Sigma, St. Louis, MO, United States) and lysed by passing through Tissue Lyser LT (Qiagen, Hilden, Germany) at maximal oscillation for $2 \mathrm{~min}$. Subsequent RNA isolation steps were performed as per manufacturer's instructions. Reverse transcription of RNA was carried out with $2 \mu \mathrm{g}$ of total RNA using random hexamers and M-MLV Reverse Transcriptase (Promega, Madison, WI, United States). Quantitative PCR (20 $\mu$ l final volume) was then conducted with DyNAmo HS SYBR Green qPCR Master Mix (Thermo Fisher Scientific, Waltham, MA, United States), using gene-specific primers (Table 1) for M1 RNA (M1-F \& R), $\Delta$ M1RNA (M1p3-F \& M1p12-R), CcpA (Cbei_0047- F \& R), and DisA (Cbei_0127- F \& R). Each of the triplicate RNA preparations was analyzed twice in a BioRad iCycler continuous fluorescence detection system (BioRad, Hercules, CA, United States), with the following cycling conditions: $95^{\circ} \mathrm{C}-15 \mathrm{~min} ; 40$ cycles of $95^{\circ} \mathrm{C}-10 \mathrm{~s}$ and $55^{\circ} \mathrm{C}-60 \mathrm{~s}$. The levels of respective RNAs were normalized to $16 \mathrm{~S}$ rRNA (Zhang and Ezeji, 2013).

\section{Determination of M1GS and DisA Copy Number per Cell}

The reference RNAs were first generated using run-off in vitro transcription. For M1GS, the reference M1 RNA was obtained using as template FokI-linearized pJA2' (Vioque et al., 1988). For the DisA mRNA, a fragment corresponding to nucleotides 301-460 of the DisA ORF was first amplified by PCR using primers Cbei_0127-F and Cbei_0127-R (Table 1) and cloned downstream of the T7 promoter in StuI-digested pBT7 (Tsai et al., 2002). Following screening for a clone with an insert in the sense orientation and subsequent confirmation by sequencing, pBT7-DisA was used as the template for PCR with primers F-ext (Table 1) and Cbei_0127-R to generate the DNA template for in vitro transcription of the DisA RNA fragment. Subsequently, based on the molecular weight and the concentration (determined using a spectrophotometer), the copy number of each transcript was calculated as previously described (Devonshire et al., 2016).

Standard curves were generated by performing RT-qPCR with 10, 20, 30, 50, 80, and 100 copies of M1 RNA and DisA transcripts and with primer sets M1-F + M1-R and Cbei_0127-F + Cbei_0127-R, respectively. The resulting quantification cycles $(\mathrm{Cq})$ were then plotted against the known copy numbers. RNA samples $(2 \mu \mathrm{g})$ isolated from $C$. beijerinckii_M1GS ${ }^{\text {DisA }}$,_M1GS ${ }^{\mathrm{CcpA}}$, or _pMTL500E were then analyzed by RT-qPCR in the same manner. Based upon the $\mathrm{Cq}$ values obtained for each reaction, the corresponding copy numbers for M1GS $S^{\text {DisA }}$ or M1GS ${ }^{\mathrm{CcpA}}$ were interpolated from the respective standard curves and normalized by subtracting the background value obtained using RNA isolated from C. beijerinckii_pMTL500E. This background correction was motivated by the expectation that neither M1GS ${ }^{\text {DisA }}$ nor M1GS ${ }^{\mathrm{CppA}}$ should be present in $C$. beijerinckii transformed with pMTL500E. The Cq values obtained for M1GS and DisA transcripts were within the range of the standard curve. By plating cells on TGY agar (as described above), we counted the colonies from cells harvested for RNA extraction and calculated the number of cells/culture volume. With this information as well as the RT-qPCR results, we could determine the number of M1GS and DisA copies per cell for the strains in this study.

\section{Rapid Amplification of cDNA 3' Ends (3' RACE) Analysis}

To assess the efficacy of the $\mathrm{HH}$ ribozyme cleavage and generation of the intended M1GS RNA, we sought to map the $3^{\prime}$ termini of the M1GS ribozymes from C. beijerinckii_M1GS ${ }^{\text {DisA }}$ and _M1GS ${ }^{\mathrm{CcpA}}$. To this end, total RNA was first incubated with polynucleotide kinase $\left(37^{\circ} \mathrm{C}-2 \mathrm{~h}\right)$ to dephosphorylate the $2^{\prime}, 3^{\prime}$-cyclic phosphate produced by $\mathrm{HH}$ cleavage. The RNA was then polyadenylated using the poly(A) Tailing Kit (Invitrogen, Carlsbad, CA, United States). Subsequently, the RNA was reverse transcribed using SuperScript II (Invitrogen) and the anchored oligo dT primer from the GeneRacer Kit (Invitrogen). The resulting cDNAs were then treated with RNase $\mathrm{H}$ before amplifying by PCR the $3^{\prime}$ ends of the ribozymes with M1GS-3F and the GeneRacer $3^{\prime}$ Primer using PrimeSTAR GXL (Takara Bio USA, Mountain View, CA, United States). This step was followed by a round of nested PCR using M1-4F and the GeneRacer 3' Nested Primer. The nestedPCR RACE product, which migrated close to the expected size on an agarose gel, was then sequenced with the M1$4 \mathrm{~F}$ primer at the OSU Genomics Shared Resources facility. Sequencing results showed that the $\mathrm{HH}$ ribozyme cleaved at the expected position and generated the desired $3^{\prime}$ termini (data not shown).

\section{Analytical Methods}

Intracellular levels of c-di-AMP were analyzed by HPLC using the Waters 2796 Bioseparations Module (Waters Corporation, Milford, MA, United States), equipped with a photodiode array (PDA) detector (Waters Corporation, Milford, MA, United States) and a 3.5- $\mu \mathrm{m}$ Xbridge C18, $150 \mathrm{~mm} \times 4.6 \mathrm{~mm}$ column (Waters Corporation, Milford, MA, United States) according to Oppenheimer-Shaanan et al. (2011). Pure c-di-AMP (BIOLOG Life Science Institute, Bremen, Germany) was used as standard. C-di-AMP was extracted from cell pellets according to Oppenheimer-Shaanan et al. (2011). Pellets were obtained from triplicate $50-\mathrm{mL}$ samples taken every $12 \mathrm{~h}$ from cultures grown in glucose + arabinose medium, and each extract was analyzed twice. Extracts were reconstituted in sterile distilled water $(400 \mu \mathrm{l})$ for HPLC analysis.

Acetone, butanol, ethanol, acetic acid, and butyric acid concentrations were quantitated using a 7890A Agilent gas chromatograph (Agilent Technologies Inc., Santa Clara, CA, United States) as described previously (Ujor et al., 2014). The GC data were analyzed using Agilent Chem Station software (Rev. B.03.02 SR2). Cell growth was determined by measuring optical density $\left(\mathrm{OD}_{600}\right)$ using a $\mathrm{DU}^{\circledR}$ spectrophotometer (Beckman Coulter, Brea, CA, United States). The concentrations of glucose, 
arabinose and xylose were determined by HPLC using the Waters 2796 Bioseparations Module (Waters Corporation, Milford, MA, United States) as previously described (Ujor et al., 2014).

\section{Mitomycin $\mathrm{C}$ and Nalidixic Acid Sensitivity Assays}

At $25 \mathrm{~h}$ post inoculation into glucose + arabinose medium, triplicate cultures of C. beijerinckii_M1GS ${ }^{\text {DisA }}$, _M1GS ${ }^{\mathrm{CcpA}}$ or _pMTL500E were adjusted to the same optical density $\left(\mathrm{OD}_{600}\right)$, and then diluted 1:500 (in $1 \mathrm{~mL}$ ) before plating out on semisolid TGY agar $[0.45 \%(\mathrm{w} / \mathrm{v})$ agar] containing erythromycin $(20 \mathrm{ng} / \mathrm{mL})$ and mitomycin C $(50,80$, or $120 \mathrm{ng} / \mathrm{mL})$ or nalidixic acid $(470,480$, or $495 \mathrm{ng} / \mathrm{mL})$. Plates were incubated for 14 to $24 \mathrm{~h}$ at $35^{\circ} \mathrm{C} \pm 1^{\circ} \mathrm{C}$ prior to counting the colony forming units.

\section{Sporulation Test}

To determine the progression of sporulation in cultures of $C$. beijerinckii_M1GS ${ }^{\text {DisA }}$,_M1GS ${ }^{\mathrm{CcpA}}$, or _pMTL500E, all three strains were grown in glucose + arabinose medium in triplicate. Samples were taken from each culture every $12 \mathrm{~h}$ and diluted 1:100 (in $1 \mathrm{~mL}$ ). A portion of the sample $(500 \mu \mathrm{l})$ was heatshocked at $75^{\circ} \mathrm{C}$ for $8 \mathrm{~min}$, cooled on ice and plated on TGY agar to determine the number of spores per sample. The remainder of each sample was plated out without heat treatment to determine the number of vegetative cells in the samples relative to the spores (heat-shocked portion). All plates contained erythromycin $(25 \mu \mathrm{g} / \mathrm{mL})$ and were incubated for $24 \mathrm{~h}$ as described above, and the colonies were counted.

\section{Statistical Analysis}

Statistical analyses were conducted with the General Linear Model (GLM) of Minitab version 17 (Minitab Inc., State College, PA, United States). Statistical analyses compared the differences in the results obtained with C. beijerinckii_M1GS ${ }^{\text {DisA }}$, _M1GS ${ }^{\mathrm{CcpA}}$, _M1GS ${ }^{\mathrm{DisA} 16}$, or _pMTL500E including butanol and $\mathrm{ABE}$ concentrations, yields and productivities, cell growth, c-di-AMP levels, copy numbers and fold changes in M1GS and DisA mRNA levels, and residual sugar concentrations after fermentation with each strain. Data were un-stacked by time and ANOVA was conducted at different time points. Tukey's test at 95\% confidence interval was applied to pairwise comparisons to determine the levels of significance. All experiments were performed in triplicate, and the errors reported reflect the standard deviation of the calculated mean.

\section{RESULTS}

\section{M1GS Design and Construction}

The M1GS approach is depicted in Figure 1A. Before designing an M1GS construct against an mRNA, it is necessary to identify a single-stranded region (preferably proximal to the start codon, $A_{+1} \mathrm{UG}$ ) in the target mRNA. Analysis of the CcpA mRNA secondary structure [nucleotides -25 to +55 of the ORF] using the mfold web server (Zuker, 2003) indicated that nucleotides +2 to +18 of its ORF are likely to be accessible for base pairing to a complementary GS. We then constructed the genes encoding two customized ribozymes: one was the test M1GS ${ }^{\mathrm{CcpA}}$ and the other a scrambled control M1GS ${ }^{\mathrm{CcpA}-\mathrm{Sc}}$. The $\mathrm{GS}^{\mathrm{CcpA}-\mathrm{Sc}}$ has the same nucleotide composition as $\mathrm{GS}^{\mathrm{CcpA}}$ but a different sequence (Figures 1B,C); we ascertained by BLAST that the scrambled GS sequence did not have a perfect (16nucleotide) contiguous match with any other mRNA in the C. beijerinckii genome.

To ensure a uniform $3^{\prime}$ terminus for each M1GS transcript generated in vivo, we placed a $\mathrm{HH}$ ribozyme downstream of M1GS. Self-cleaving HH ribozymes have been used to synthesize RNAs with well-defined termini in vitro and in vivo. Both $\mathrm{M} 1 \mathrm{GS}^{\mathrm{CcpA}}$ and $\mathrm{M} 1 \mathrm{GS}^{\mathrm{CcpA}-\mathrm{Sc}}$ constructs (Figures 1B,C) were cloned into pWUR459 (Siemerink et al., 2011), displacing the resident acetoin reductase gene, and placing the constructs under the control of the acetoacetate decarboxylase $(a d c)$ promoter, which is active during solventogenesis. As an additional negative control, we used pMTL500E, the vector from which pWUR459 originated. All three plasmids were introduced into $C$. beijerinckii by electroporation to generate the strains C. beijerinckii_M1GS ${ }^{\mathrm{CcpA}}$, _M1GS ${ }^{\mathrm{CcpA} A-S c}$, and _pMTL500E.

Before examining the effect of CcpA knockdown on solventogenesis, we determined that M1GS ribozymes were expressed in C. beijerinckii_M1GS ${ }^{\mathrm{CcpA}}$ and $\_\mathrm{M} 1 \mathrm{GS}^{\mathrm{CcpA}}-\mathrm{Sc}$ relative to the vector control strain C. beijerinckii_pMTL500E (Table 2), and that they were synthesized with the correct termini. Although some earlier reports used only a minimal $\mathrm{HH}$ catalytic core (Uhlenbeck, 1987), since loop sequences outside the catalytic core were found to enhance the rate of selfcleavage at physiological $\mathrm{Mg}^{2+}$ concentrations (Khvorova et al., 2003), we opted for a naturally occurring, loop-containing $\mathrm{HH}$ ribozyme found in Arabidopsis thaliana (Aral, $\mathrm{k}_{\mathrm{obs}} \sim 2 \mathrm{~min}^{-1}$ at $25^{\circ} \mathrm{C}$ in $0.6 \mathrm{mM} \mathrm{Mg}^{2+}$ ) (Przybilski et al., 2005) with some modifications (Figure 1A, inset). Indeed, $3^{\prime}$ RACE followed by sequencing proved that Aral, albeit of plant origin, functions efficiently in C. beijerinckii and cleaves at the expected position to generate a precise $3^{\prime}$ terminus (data not shown). To our knowledge, such use of $\mathrm{HHs}$ in the M1GS approach has not been reported.

\section{M1GSCcpA Elicited Knockdown of CcpA mRNA and a Modest Increase in ABE Production}

We used RT-qPCR with CcpA-specific primers (Table 1) that flank the targeted region to determine the expression of CcpA mRNA in the three C. beijerinckii transformants. We found that the CcpA mRNA level in C. beijerinckii_M1GS ${ }^{\mathrm{CcpA}}$ decreased 2.8-fold $(p<0.05)$ when compared to the other strains (Table 2). While examining the ABE production profiles for all strains grown on various sugars, the largest increase observed in C. beijerinckii_M1GS ${ }^{\mathrm{CcpA}}$ relative to _pMTL500E was $\sim 1.2$-fold $(p<0.05)$ when grown on glucose + arabinose (Figure 2 and Table 3). Unexpectedly, we also observed a $\sim 1.5$-fold $(p<0.05)$. Increase in ABE production by 
TABLE 2 | Determination of fold-change for CcpA and DisA mRNA level and of the cellular copy number for M1GS and DisA transcripts.

\begin{tabular}{lcccc}
\hline C. beijerinckii strain & CcpA mRNA (fold change) & DisA mRNA (fold change) & M1GS transcript (copies/cell) & DisA mRNA (copies/cell) \\
\hline pMTL500E & $1.0 \pm 0.0$ & $1.0 \pm 0.0$ & $0.0 \pm 0.0$ & $791.0 \pm 78.0$ \\
M1GSCcpA & $-2.8 \pm 0.4$ & $1.0 \pm 0.0$ & $83 \pm 9$ & $828.0 \pm 74.0$ \\
M1GSDisA & $1.0 \pm 0.0$ & $-44.0 \pm 4.4$ & ND & $15.3 \pm 2.8$ \\
MIGSDisA16 & $1.0 \pm 0.0$ & $-43.5 \pm 1.0$ & ND & ND \\
MMIGSDisA16 & $1.0 \pm 0.0$ & $-1.5 \pm 0.0$ & ND
\end{tabular}

ND, not determined. Tukey's pairwise comparison was applied to the means of CcpA mRNA fold changes, M1GS transcript copies, and DisA mRNA copies. RNA copy number was calculated using RT-qPCR (see text for details). All fold changes are relative to C. beijerinckii_pMTL500E. Errors denote the standard deviation of the mean $(n=3)$.

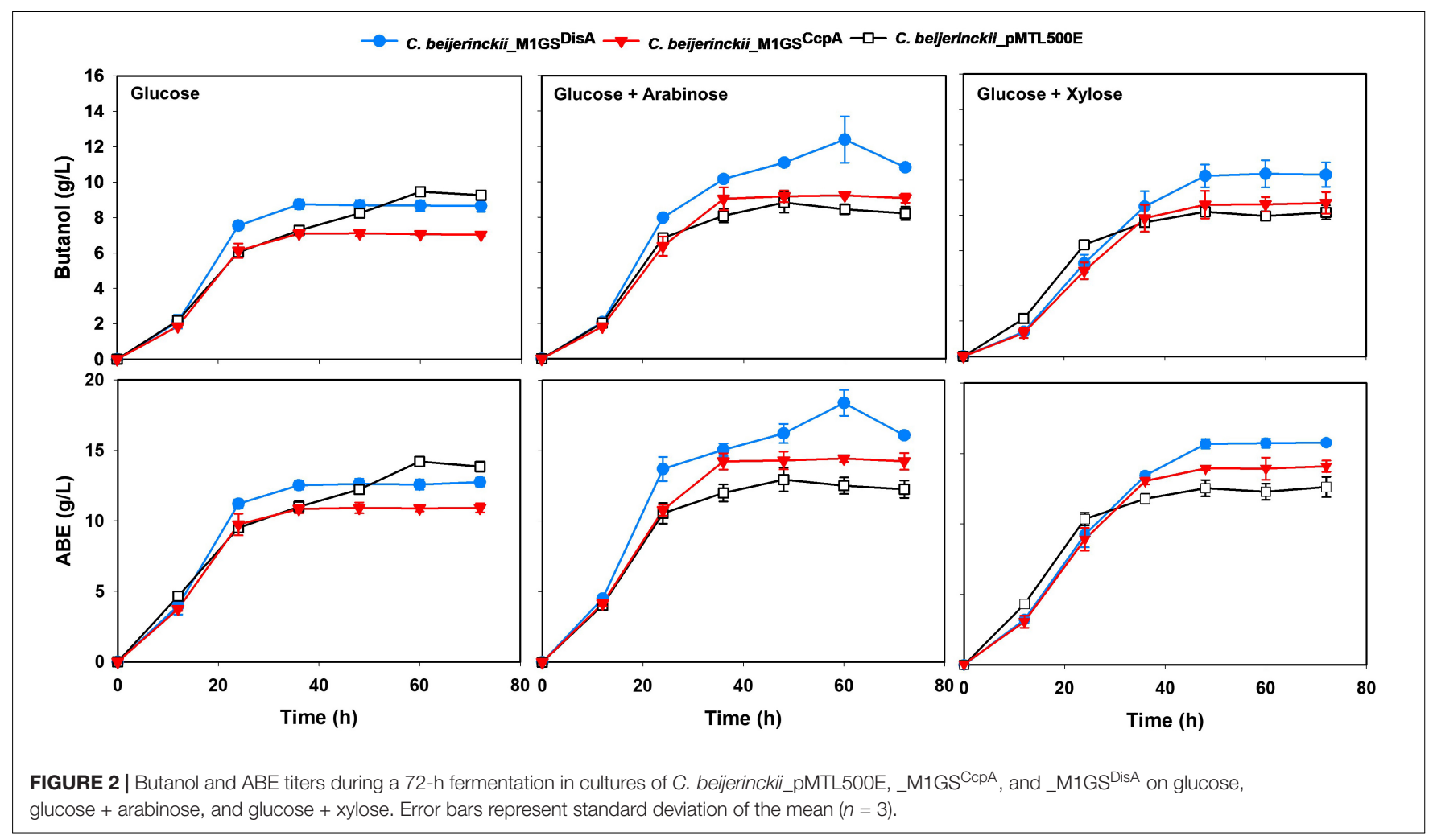

C. beijerinckii_M1GS ${ }^{\mathrm{CcpA}-\mathrm{Sc}}$ compared to the vector control, both grown on glucose + arabinose (Figure 2 and Table 3 ). We leveraged this adventitious finding to direct our study differently.

\section{M1GS ${ }^{\mathrm{CcpA}-S c}$ (M1GS $^{\text {DisA }}$ ) Leads to a Pronounced Decrease in DisA mRNA Level}

To understand the basis for increased $\mathrm{ABE}$ production by $C$. beijerinckii_M1GS ${ }^{\mathrm{CcpA}-\mathrm{Sc}}$, we performed a BLASTn analysis using the $\mathrm{GS}^{\mathrm{CcpA}-\mathrm{Sc}}$ sequence as a query against the C. beijerinckii genome. Although we found several genes with a complementarity of nine or more contiguous nucleotides, only six of them seemed likely to affect fermentation. When RT-qPCR analysis of these six mRNAs was conducted (Supplementary Table 1), only Cbei_0127 (DisA) mRNA was found to decrease drastically (44-fold; $p<0.05)$ in C. beijerinckii_M1GS ${ }^{\mathrm{CcpA}-\mathrm{Sc}}$ relative to $C$. beijerinckii_M1GS ${ }^{\mathrm{CcpA}}$ and _pMTL500E. This finding prompted us to rename M1GS ${ }^{\mathrm{CcpA}-\mathrm{Sc}}$ as M1GS ${ }^{\mathrm{DisA}}$.

In an independent RT-qPCR experiment, we used an in vitro transcribed fragment of the DisA mRNA as a reference for a standard curve and determined that $\sim 800$ copies of DisA mRNA are present per cell in C. beijerinckii_M1GSCcpA and _pMTL500E, but only 15 copies in C. beijerinckii_M1GS ${ }^{\text {DisA }}$, representing a 53-fold $(p<0.05)$ downregulation mediated by M1GS ${ }^{\text {DisA }}$ (Table 2). With in vitro transcribed M1 RNA as a reference for a standard curve, we found that the normalized copy number of M1GS per cell is 0,83 , and 87 , in C. beijerinckii_pMTL500E,_M1GS ${ }^{\mathrm{CcpA}}$, and _M1GS ${ }^{\mathrm{DisA}}$, respectively (Table 2). The decrease from 828 to 15 copies of DisA mRNA mediated by 87 copies of $\mathrm{M}_{1 \mathrm{GS}}{ }^{\text {DisA }}$ in C. beijerinckii_M1GS ${ }^{\text {DisA }}$ must entail multiple turnover of the ribozyme (at least nine rounds). Although multiple turnover was an implicit expectation for M1GS, in vivo evidence has not been documented before. 


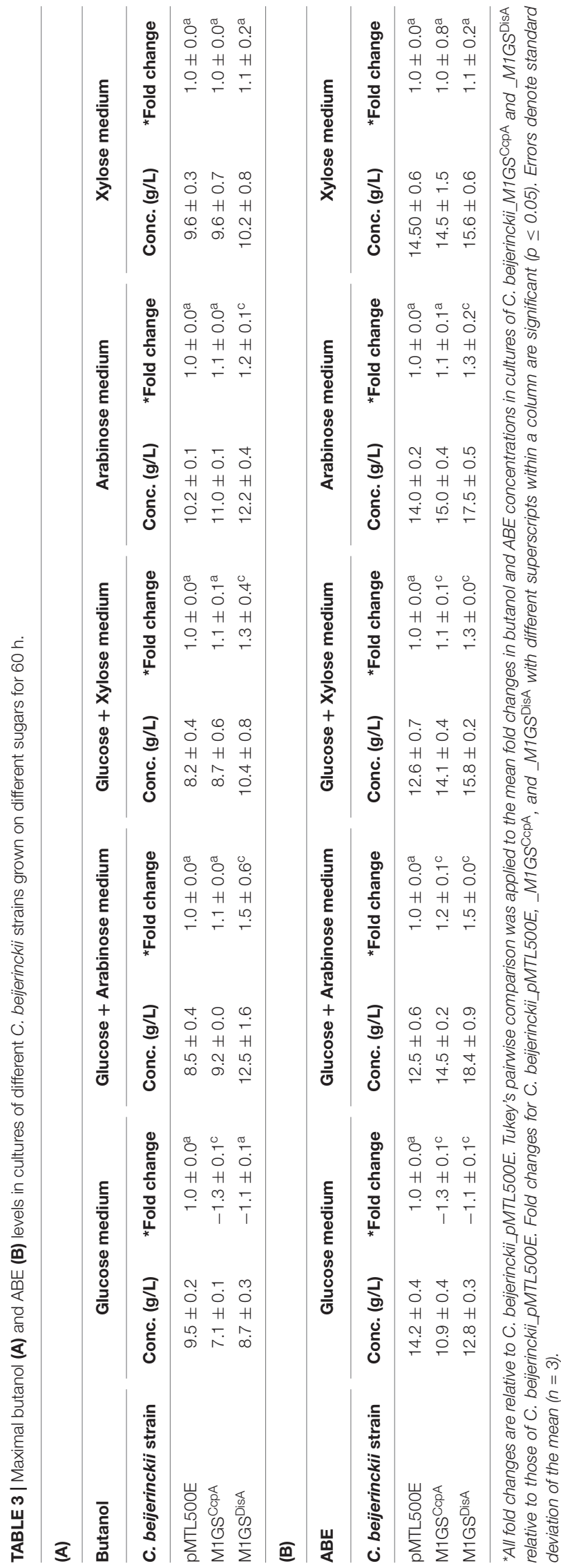

\section{C. beijerinckii_M1GS ${ }^{\text {DisA }}$ Displayed a Decreased c-di-AMP Level, Increased Sensitivity to DNA-Damaging Antibiotics, and a Slower Sporulation Rate}

Since DisA is a diadenylate cyclase (DAC) that synthesizes c-di-AMP (Bejerano-Sagie et al., 2006; Oppenheimer-Shaanan et al., 2011), its knockdown should result in decreased c-diAMP production. Indeed, when intracellular levels of c-di-AMP in 24-h cultures of C. beijerinckii_M1GS ${ }^{\text {DisA }}$,_M1GS ${ }^{\mathrm{CcpA}}$, and _pMTL500E were quantitated by HPLC, we observed a 7-fold $(p<0.05)$ decrease in C. beijerinckii_M1GS ${ }^{\text {DisA }}$ compared to the other two strains (Figure 3A).

Because DisA scans genomic DNA and initiates the repair of lesions, we also postulated that C. beijerinckii_M1GS ${ }^{\text {DisA }}$ would be more susceptible to DNA-damaging agents due to DisA knockdown. Therefore, C. beijerinckii_M1GS ${ }^{\text {DisA }}$ and _M1GS ${ }^{\mathrm{CcpA}}$ were challenged with mitomycin $\mathrm{C}$ and nalidixic acid, two well-established DNA-damaging antibiotics. Both drugs drastically decreased the viability of $C$. beijerinckii_M1GS ${ }^{\text {DisA }}$ compared to _M1GS ${ }^{\mathrm{CcpA}}$ (Figure 3B and Supplementary Figure 1). At $120 \mathrm{ng} / \mathrm{mL}$ of mitomycin $C$, the viability of M1GS ${ }^{\text {DisA }}$ decreased by $99.9 \%(p<0.05)$. A similar effect was observed with nalidixic acid, which decreased the viability of $C$. beijerinckii_M1GS ${ }^{\text {DisA }}$ by $99.8 \%(p<0.05)$ at $470 \mathrm{ng} / \mathrm{mL}$ and by $100 \%$ at $480-495 \mathrm{ng} / \mathrm{mL}$. These results indicate that C. beijerinckii_M1GS ${ }^{\text {DisA }}$ is hypersensitive to DNAdamaging antibiotics.

DisA monitors genomic integrity particularly at the onset of sporulation. To allow a cell to fix damages to DNA that might disrupt its replication or cause defects in chromosome partitioning, DisA halts sporulation by delaying the activation of Spo0A, a master transcriptional activator critical for sporulation. Thus, DisA knockdown is expected to alter the sporulation dynamics in C. beijerinckii_M1GS ${ }^{\text {DisA }}$. Since cultures of solventogenic clostridia exist as mixtures of vegetative cells and spores upon transition to solventogenesis, we assessed the progression of sporulation in cultures of C. beijerinckii_M1GS ${ }^{\mathrm{DisA}}$, _M1GS ${ }^{\mathrm{CcpA}}$, and _pMTL500E over a 60-h fermentation (Figure 3C). As expected, C. beijerinckii_M1GS $S^{\text {DisA }}$ showed a delay relative to C. beijerinckii_pMTL500E (Figure 3C). We observed 7.4-, 2.5- and 1.6-fold decrease in percent sporulation at 24, 36, and $48 \mathrm{~h}$, respectively, for C. beijerinckii_M1GS ${ }^{\text {DisA }}$ compared to C. beijerinckii_pMTL500E $(p<0.05)$. Although CcpA is known to partake in sporulation, no substantial delay was found in C. beijerinckii_M1GS ${ }^{\mathrm{CcpA}}$ cultures compared to the sporulation rate found in C. beijerinckii_pMTL500E cultures. It is also possible that the $\sim 3$-fold decrease in CcpA mRNA level is insufficient to cause a change in the sporulation dynamics.

\section{Both C. beijerinckii_M1GS ${ }^{\mathrm{CcpA}}$ and M1GS ${ }^{\text {DisA }}$ Exhibited Increased Solvent Production in Pentose-Containing Media}

The effects of CcpA and DisA knockdown on butanol and $\mathrm{ABE}$ production were assessed while growing on media 


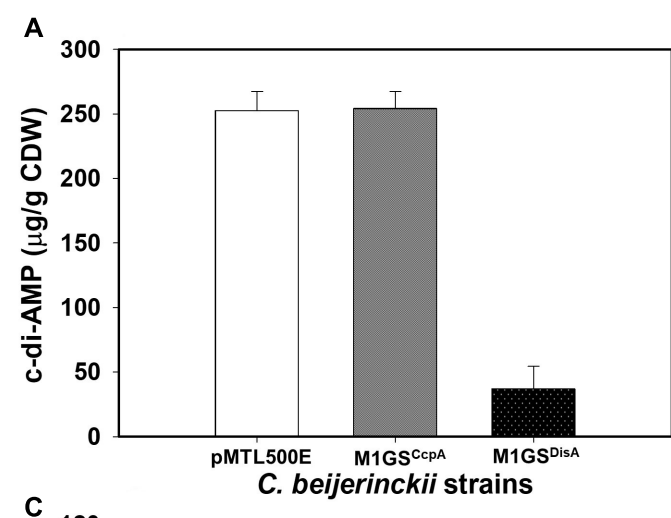

B Mitomycin C $(120 \mathrm{ng} / \mathrm{mL})$
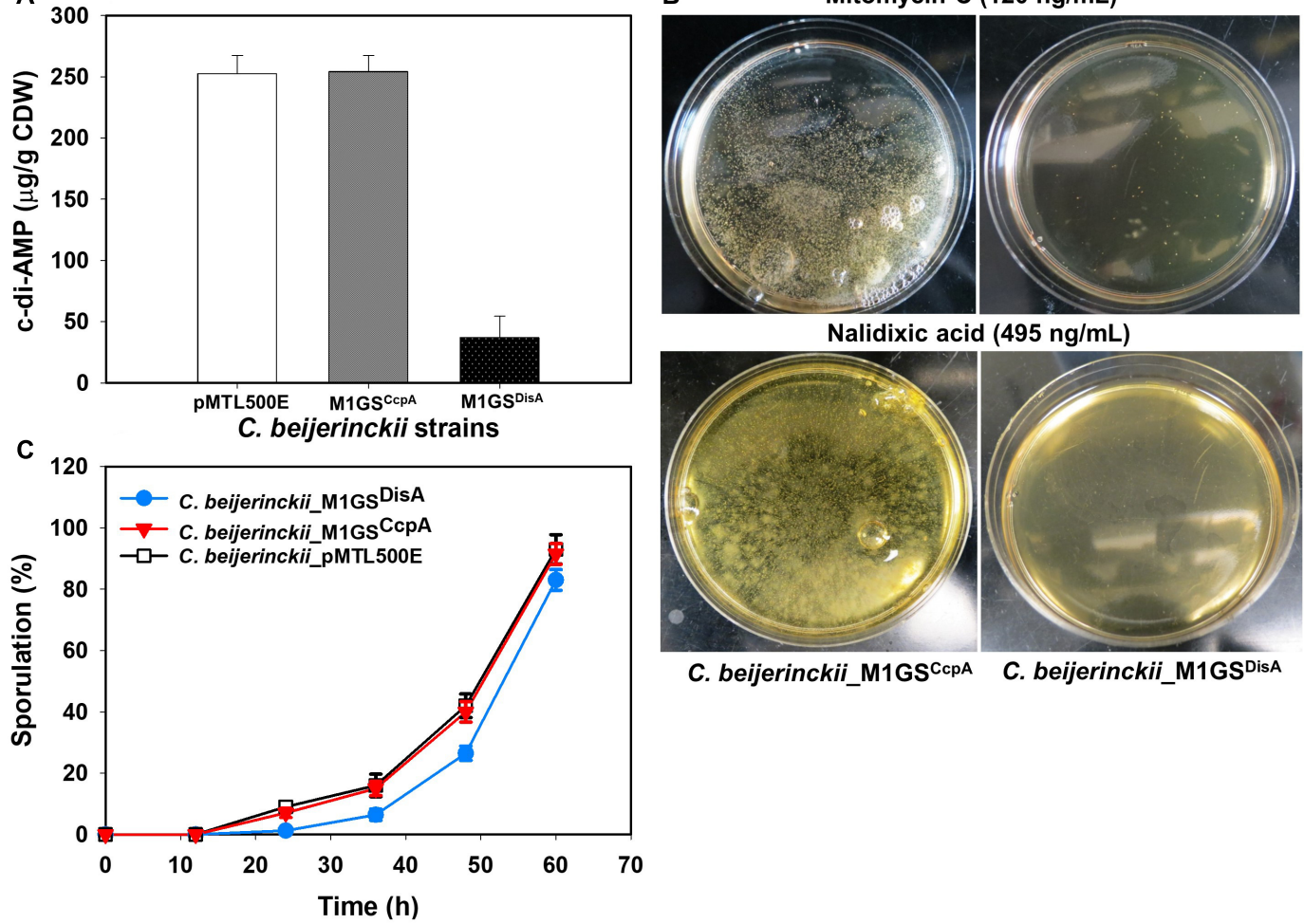

C. beijerinckii_M1GSCcpA C. beijerinckii_M1GS ${ }^{\text {DisA }}$

FIGURE 3 | Phenotypic changes elicited by M1GSDisA. (A) Intracellular c-di-AMP levels in C. beijerinckii_M1GSDisA decreased 7-fold relative to C. beijerinckii _M1GS ${ }^{\mathrm{CcPA}}$ and _pMTL500E at $24 \mathrm{~h}$ of growth. CDW, cell dry weight. (B) C. beijerinckii_M1GS ${ }^{\text {DisA }}$ was more sensitive to mitomycin C and nalidixic acid than C. beijerinckii_M1GS ${ }^{C C P A}$. At the specified concentrations, both antibiotics caused $\sim 100 \%$ loss of cell viability in C. beijerinckii_M1GS ${ }^{\text {DisA }}$ (see Supplementary Figure 1 for more details). Generation of carbon dioxide and hydrogen during cellular growth and metabolism caused bubbles on C. beijerinckii_M1GSCcpA plates. (C) Sporulation profiles of $C$. beijerinckii_M1GS DisA relative to $C$. beijerinckii_M1GSCcpA and _pMTL500E. Error bars represent standard deviation of the mean $(n=3)$.

with single (glucose, arabinose, or xylose) and mixed sugars (glucose + arabinose or glucose + xylose) as carbon source(s). Interestingly, butanol production by both C. beijerinckii_M1GS ${ }^{\mathrm{CcpA}}$ and_M1GS ${ }^{\mathrm{DisA}}$ was lower than the control (C. beijerinckii_pMTL500E) when grown on glucose (Table 3), although C. beijerinckii_M1GS ${ }^{\text {Dis A }}$ initially (12$48 \mathrm{~h}$ ) produced more than the other two strains (Figure 2). Except for C. beijerinckii_M1GS ${ }^{\mathrm{CcpA}}$ being on par with the control in xylose medium (Figure 4), C. beijerinckii_M1GS ${ }^{\mathrm{CcpA}}$ and_M1GS ${ }^{\text {DisA }}$ showed higher butanol production than the control strain in all pentose-containing media (Figures 2, 4 and Table 3 ). This difference was most pronounced in media containing arabinose, either alone or in combination with glucose (Figures 2, 4). In the arabinose medium, maximal butanol concentration was 1.2-fold $(p<0.05)$ higher in C. beijerinckii_M1GS ${ }^{\text {DisA }}$ than $C$. beijerinckii_pMTL500E; remarkably, this change increased to 1.5 -fold $(p<0.05)$ with the addition of glucose (Figures 2, 4 and Table 3A). In xylose medium, C. beijerinckii_M1GS ${ }^{\text {DisA }}$ achieved a maximal butanol titer that is 1.1-fold higher than $C$. beijerinckii_pMTL500E; this change increased to 1.3 -fold $(p<0.05)$ with the addition of glucose. Thus, butanol production notably increased by either $50 \%$ or $30 \%$ in C. beijerinckii_M1GS ${ }^{\text {DisA }}$ grown in media with either glucose + arabinose or glucose + xylose, respectively, when compared to the control strain; the basis for this solventogenesis difference between the two pentoses remains to be determined by future transcriptomic studies. In contrast, the gains with $C$. beijerinckii_M1GS ${ }^{\mathrm{CcpA}}$ were more modest (less than $10 \%$ regardless of the combinations tested). In all fermentations, the extent of changes in ABE levels mirrored the corresponding butanol titers (Figures 2, 4 and Table 3). Calculated yield, productivity, and residual sugars in cultures of C. beijerinckii_M1GS ${ }^{\mathrm{CcpA}}$,_M1GS ${ }^{\text {DisA }}$ and _pMTL500E after a 60 - $\mathrm{h}$ fermentation are consistent with the solvent production profiles (Supplementary Tables 2, 3).

To further characterize the phenotypes of C. beijerinckii_M1GS ${ }^{\mathrm{CcpA}}$, _M1GS ${ }^{\mathrm{DisA}}$, and _pMTL500E, their optical densities $\left(\mathrm{OD}_{600}\right)$ during fermentation on the various carbon substrates mentioned above were measured (Supplementary Figure 2A). Growth for all three strains was comparable in glucose- and arabinose-containing media. C. beijerinckii_M1GS ${ }^{\mathrm{Ccp} A}$ grew well in glucose + arabinose medium, whereas the maximal $\mathrm{OD}_{600}$ values of the other two strains (C. beijerinckii_M1GS ${ }^{\text {DisA }}$ and _pMTL500E) were both $\sim 1.2$-fold lower $(p<0.05)$ than the glucosecontaining medium. In glucose + xylose and xylose-alone media, C. beijerinckii_M1GS ${ }^{\text {DisA }}$ showed the poorest growth, with maximal $\mathrm{OD}_{600}$ values up to 1.4 -fold lower $(p<0.05)$ than 


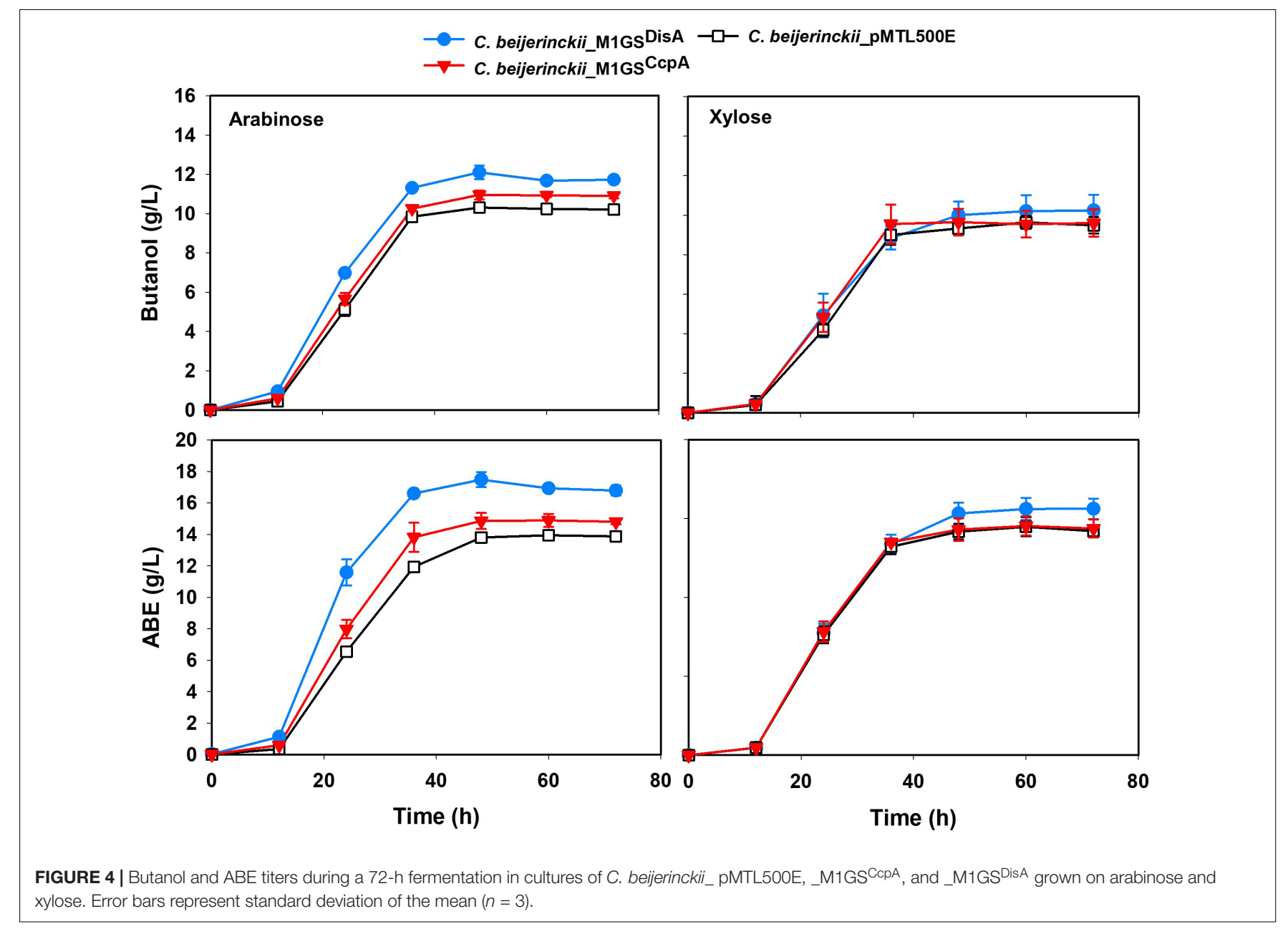

those of C. beijerinckii_M1GSCcpA or _pMTL500E grown on different combinations (Supplementary Figure 2A). We could not gain clear insights as to solventogenesis gains based on these growth curves.

\section{Increased Complementarity in GS ${ }^{\text {DisA }}$ Did Not Lead to Solventogenic Gain}

Given the enhanced solventogenesis elicited by M1GS ${ }^{\text {DisA }}$ even though its GS has only 9-bp complementarity with the DisA mRNA, we then examined whether an M1GS with additional base pairing would be even more effective. To this end, we constructed C. beijerinckii_M1GS ${ }^{\text {DisA } 16}$ that has a full 16nucleotide complementarity to DisA mRNA. As an additional control, we generated $C$. beijerinckii_ $\triangle \mathrm{M} 1 \mathrm{GS} S^{\mathrm{DisA} 16}$ in which the latter half of M1 RNA was deleted to render it inactive; this control helps determine the antisense effect of the GS portion. We found that DisA mRNA decreased $\sim 44$ - and 1.5 -fold in C. beijerinckii_M1GS ${ }^{\text {DisA } 16}$ and ${ }_{\Delta} \mathrm{M} 1 \mathrm{GS} S^{\text {DisA } 16}$, respectively (Table 2). Despite a comparable knockdown in DisA mRNA level relative to C. beijerinckii_M1GS ${ }^{\text {DisA }}$ (53-fold), C. beijerinckii_M1GS ${ }^{\text {DisA } 16}$ showed a very different growth and solvent profile relative to C. beijerinckii_M1GS ${ }^{\text {DisA }}$.
The different strains of $C$. beijerinckii studied herein exhibited varying growth profiles with different sugar substrates. For instance, cultures of $C$. beijerinckii_M1GS ${ }^{\text {DisA } 16}$ reached maximum optical densities at $60 \mathrm{~h}$ when grown on glucose and glucose + arabinose, whereas C. beijerinckii_M1GS ${ }^{\text {DisA }}$, _ $\triangle{\mathrm{M} 1 G S^{\mathrm{DisA} 16} \text {, _M1GS }}^{\mathrm{CcpA}}$, and _pMTL500E reached maximum optical densities at $24 \mathrm{~h}$ on glucose and glucose + arabinose, except for $C$. beijerinckii_ $\Delta \mathrm{M} 1 \mathrm{GS} S^{\mathrm{DisA}}$ that grew to a maximum optical density at $36 \mathrm{~h}$ on glucose and arabinose (Supplementary Figures 2A,B). Conversely, when grown on glucose + xylose,_M1GS ${ }^{\text {DisA } 16}$ attained greater optical density and in considerably less time (36 h), when compared to its growth on glucose or glucose + arabinose (Supplementary Figures 2A,B).

To further assess the effects of DisA knockdown on solvent production, we compared the solvent profiles of C. beijerinckii_ $\triangle \mathrm{M} 1 \mathrm{GS} S^{\mathrm{DisA} 16}$ and $\mathrm{M}_{1 \mathrm{GS}} \mathrm{S}^{\mathrm{Dis} 16}$ to those of ${ }_{\text {M1GS }}{ }^{\text {DisA }}$,_M1GS ${ }^{\mathrm{CcpA}}$, and _pMTL500E in media containing glucose, glucose + arabinose, and glucose + xylose (Figures 2, 4 and Supplementary Figure 3). Like its growth profile (Supplementary Figure 2B), C. beijerinckii_M1GS DisA16 exhibited a considerable lag in solvent accumulation (Supplementary Figure 3) when grown on glucose or 
glucose + arabinose but not on glucose + xylose. Notably, C. beijerinckii_AM1GS $S^{\text {isA } 16}$ achieved similar maximum solvent concentrations as C. beijerinckii_M1GS $S^{\text {DisA } 16}$ and ${ }_{2} 1_{G S} S^{\text {DisA }}$ when grown on glucose and glucose + xylose (Supplementary Figure 3). However, when all three strains were grown on glucose + arabinose, C. beijerinckii_M1GS ${ }^{\text {DisA }}$ produced significantly more butanol and ABE than $C$. beijerinckii_AM1GS $S^{\text {DisA } 16}$ and_M1GS ${ }^{\text {DisA } 16}$.

\section{DISCUSSION}

Although we fulfilled our goal of improving ABE production in C. beijerinckii grown on mixed sugars, it was accomplished more through fortuitous knockdown of DisA than of CcpA, which was our intended target originally for dampening CCR. While a modest $\mathrm{ABE}$ increase was observed with CcpA downregulation, our results provide insights into the M1GS-based knockdown approach in C. beijerinckii and the hitherto unknown role of DisA (via c-di-AMP) in solventogenesis (Figure 5).

The M1GS-based mRNA degradation approach has been used successfully to cleave mRNAs in bacteria, mammalian cells, and mice (Liu, 2010). Nevertheless, our finding of the 53-fold decrease in the DisA mRNA level in C. beijerinckii elicited by M1GS ${ }^{\text {DisA }}$ is notable for a few reasons. First, we show the utility of this method in an anaerobic, Gram-positive bacterium and demonstrate its merit as a tool for studying the physiology and metabolic engineering of Clostridium species. Second, our copy number determination of the DisA mRNA and M1GS ${ }^{\text {DisA }}$ confirms the unproven expectation of multiple turnover by this ribozyme in vivo (Table 2). Third, the M1GS method typically aims for 13-15 base pairs between the GS and the target mRNA to achieve optimal binding and cleavage, with the caveat that long stems favorable for GS-mRNA complex formation might inhibit turnover by preventing product release. That M1GS DisA can form only 9 base pairs with the DisA mRNA (Figure 1C) may account for the efficient turnover that we observed; it is possible that intracellular factors (e.g., chaperones) contribute favorably either to the annealing and thermodynamic stability of the GS-mRNA complex or to product dissociation. While such short GS-mRNA duplexes raise the specter of off-target effects, this concern is partly alleviated by accessibility considerations. In fact, the degree of knockdown observed for DisA mRNA suggests that the target sequence on this mRNA is accessible. This expectation is consistent with our observation that extending the GS-DisA mRNA complementarity from 9- (Figure 1C) to 16-base pairs (Figure 1D) resulted in a similar extent of DisA mRNA knockdown $(\sim 44$-fold), relative to the plasmid control strain (C. beijerinckii_pMTL500E). Fourth, these DisA-targeted GSs bind to the 334-349 region of DisA mRNA (numbering with reference to the start codon; Figures 1C,D), whereas GSs are typically designed to target nucleotides immediately downstream of the start codon because they are often single-stranded to ensure high translatability. The efficient knockdown with these DisAtargeted GSs suggests that local secondary structure elsewhere in the mRNA, which is hard to predict under cellular conditions, might offer more accessible targets (Cobaleda and SánchezGarcía, 2000; Lundblad et al., 2008). New methods that map RNA secondary structure in vivo will be valuable in this regard (Spitale et al., 2013; Watters et al., 2016; Zhao et al., 2019). Last, in vitro studies suggest that M1GS prefers to cleave between a pyrimidine and a guanosine (Figure 1B; Li and Altman, 1996), but this cleavage site requirement is not absolute. Indeed, based on the predicted targeting site in the DisA mRNA (Figures 1C,D), it appears that this is not a strict requirement in vivo.

It is surprising that while we set out to knock down CcpA in C. beijerinckii to abolish or at least dampen CCR, we achieved only a 3-fold decrease in the CcpA mRNA level with M1GS ${ }^{\mathrm{CcpA}}$ when $\mathrm{M} 1 \mathrm{GS}^{\mathrm{DisA}}$ could reduce the DisA mRNA level by 53-fold. Nevertheless, the 3-fold decrease in CcpA mRNA levels was accompanied by a 10-20\% increase in $\mathrm{ABE}$ production compared to the control when grown on arabinose, glucose + arabinose, or glucose + xylose media (Figures 2, 4 and Table 3). The fact that the increase was associated with pentose-containing media suggests that M1GS ${ }^{\text {CppA }}$ was able to dampen CCR. That M1GS ${ }^{\text {CcpA }}$ was not more effective could be explained by gene duplication in C. beijerinckii (Hall et al., 2009; Shi et al., 2010). While our customized M1GS ${ }^{\mathrm{CcpA}}$ was designed to target Cbei_0047, which is annotated to encode a CcpA/alanine racemase, the $C$. beijerinckii genome has seven other genes annotated to encode putative alanine racemases that have sequence similarity to Cbei_0047 as well as to the C. acetobutylicum CcpA (Supplementary Table 4). Given that all these seven proteins harbor DNA-binding helix-turn-helix and sugarbinding domains like those found in Cbei_0047, a 3-fold downregulation of the CcpA mRNA encoded by Cbei_0047 may not be sufficient to eliminate CCR.

Decreased DisA mRNA and c-di-AMP levels, increased sensitivity to DNA-damaging antibiotics, and delayed sporulation in C. beijerinckii_M1GS ${ }^{\text {DisA }}$ are consistent with the 53-fold knockdown of DisA mRNA. However, the 7-fold decrease in cellular c-di-AMP level in C. beijerinckii_M1GS ${ }^{\text {DisA }}$ was lower than expected but easily rationalized. While most organisms have only one diadenylate cyclase (DAC; a c-di-AMP-producing enzyme), Clostridium and Bacillus species possess two to three DACs, all subject to spatio-temporal regulation (Corrigan and Gründling, 2013; Mehne et al., 2013). In fact, the presence of c-di-AMP in a DisA-null mutant of $B$. subtilis during vegetative growth confirmed the involvement of other DACs in c-di-AMP production (Oppenheimer-Shaanan et al., 2011). To determine if there are additional DACs in the $C$. beijerinckii genome, we searched for proteins annotated with a DAC domain (DUF147; Mehne et al., 2013). In addition to Cbei_0127 (DisA), we found only Cbei_0200, a conserved hypothetical protein, to have this domain. Cbei_0200 was also the only C. beijerinckii protein uncovered in a BLASTp search when the sequences of Cbei_0127 (DisA) and the three B. subtilis DACs (CdaA, $\mathrm{CdaS}$, and DisA) were each used as a query. While the protein product of Cbei_0200 might be a DAC homolog that contributes to intracellular c-di-AMP levels, it is unlikely that Cbei_0200 encodes a DisA homolog as it shares only $22 \%$ similarity with Cbei_0127. Importantly, the poor complementarity between Cbei_0200 and GS ${ }^{\text {DisA }}$ would allow Cbei_0200 to escape downregulation by $\mathrm{M} 1 \mathrm{GS} \mathrm{SisA}^{\mathrm{D}}$ and to continue contributing to the cellular c-di-AMP level in C. beijerinckii_M1GS ${ }^{\text {DisA }}$. As in 


\section{High $[$ DisA $] \longrightarrow$ High [c-di-AMP] High stress sensitivity $\longrightarrow$ Limited solventogenesis}

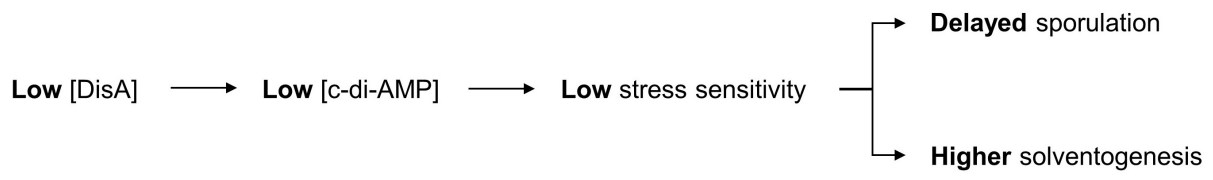

FIGURE 5 | Model for the role of C-di-AMP in ABE production. The depiction includes the normal sequence of events during C-di-AMP production in C. beijerinckii and the role of c-di-AMP in the initiation of sporulation, which impacts the duration of ABE biosynthesis. Decrease in c-di-AMP production following DisA knockdown in C. beijerinckii_M1GS ${ }^{\text {DisA }}$ would delay activation of SpoOA, and hence, the onset of sporulation. This delay would therefore extend the solventogenic phase, thereby allowing increased accumulation of ABE pre-sporulation.

B. subtilis, where DisA is expressed predominantly at high cell density and at the onset of sporulation (Bejerano-Sagie et al., 2006; Mehne et al., 2013), decreases in the c-di-AMP level in C. beijerinckii_M1GS ${ }^{\text {DisA }}$ relative to the control strains were pronounced at high cell density (7-fold at $24 \mathrm{~h}$ of growth) and at the peak of sporulation (5-fold at $60 \mathrm{~h}$; Figure $\mathbf{3 A}$ and Supplementary Figure 4).

In some media, C. beijerinckii_M1GS ${ }^{\text {DisA }}$ grew slower but produced more $\mathrm{ABE}$ than other strains (Figures 2, 4 and Supplementary Figures 2, 3). c-di-AMP is essential for growth in rich media but is dispensable in minimal media (Whiteley et al., 2015). Decreased c-di-AMP level is the likely cause for the poorer growth in the first $24 \mathrm{~h}$ when nutrients in the media is high. We can also rationalize our observation that a more efficient channeling of carbon to $\mathrm{ABE}$ biosynthesis over biomass accumulation exists in this strain, a desirable trait for large-scale fermentation. As c-di-AMP can directly inactivate pyruvate carboxylase (Sureka et al., 2014), decreasing the level of this secondary messenger could support the TCA cycle and thereby solventogenesis in C. beijerinckii_M1GS ${ }^{\text {DisA }}$. In addition, high c-di-AMP level leads to increased stress sensitivity, especially to high salt concentrations (and, perhaps, other stressors including ABE products); the low c-di-AMP level in C. beijerinckii_M1GS ${ }^{\text {DisA }}$ likely mitigated such stress sensitivity. Coupled to the delayed onset of sporulation mediated by DisA knockdown (Figure 3C), solvent production in C. beijerinckii_M1GS ${ }^{\text {DisA }}$ can continue unabated longer than other strains.

While C. beijerinckii_M1GS ${ }^{\text {DisA }}$ and_M1GS ${ }^{\text {DisA16 }}$ showed a similar degree of DisA mRNA fold change ( $\sim 44$-fold decrease; Table 2), their growth and solvent profiles (Figures 2, 4) are seemingly disparate but share a pattern. First, their slow growth, though worse in the latter strain, occurred only at the early stages of culturing. Second, while higher solvent production is evident in C. beijerinckii_M1GS ${ }^{\text {DisA }}$ after $12 \mathrm{~h}$ of growth, C. beijerinckii_M1GS ${ }^{\text {DisA } 16}$ displayed an initial lag but the ABE production increased thereafter to at least a level that matched that of other strains. Both observations could be explained by decreased c-di-AMP levels as discussed above: poor growth in rich media and a rapid increase in $\mathrm{ABE}$ productivity in later stages. The reason for differences in phenotypes between C. beijerinckii_M1GS $S^{\text {DisA }}$ and C. beijerinckii_M1GS $S^{\text {DisA16 }}$ is unclear but may involve stronger off-target effects by GS DisA16. Support for this possibility comes from the observation that of the five mRNAs encoding transporters examined by RTqPCR as possible off-targets of M1GS ${ }^{\text {DisA }}$ (Supplementary Table 1), three (including ABC transporter component of monosaccharide transport system and ATP-binding cassette domain of the histidine-glutamine transporters) showed severalfold downregulation. These findings suggest that for organisms with AT-rich genomes such as $C$. beijerinckii, promiscuity with the M1GS approach is inevitable. Even a naturally occurring small RNA in solventogenic clostridia was found to be a pleiotropic regulator due to its ability to target multiple mRNAs simultaneously (Yang et al., 2020). Thus, the specificity issues that we found unpredictable might be attributable to the compositional make-up of the transcriptome and repertoire of cellular factors in C. beijerinckii.

Asporogenic strains of solventogenic clostridia have long been considered ideal for continuous fermentation and longer-lasting batch fermentation with improved sugar utilization and $\mathrm{ABE}$ production. However, obtaining such a strain has thus far proven elusive. Our observation of enhanced $\mathrm{ABE}$ production by knocking down a gene not directly involved in the onset of sporulation (Figure 5) merits further investigation and highlights the importance of understanding the intricate coupling between sporulation and solventogenesis. While DisA knockdown exhibited improved $\mathrm{ABE}$ production, it also increased sensitivity to DNA damage (Figure 3B). Future studies to decrease intracellular c-di-AMP levels either by downregulating other DACs (not involved in genome scanning and DNA repair) or by upregulating the c-di-AMP phosphodiesterases may be a viable and appealing alternative.

Overall, our results confirm that DisA is a significant player in the regulation of solvent production in $C$. beijerinckii. It is plausible that a similar phenomenon exists in other solventogenic Clostridium species. While our findings demonstrate the utility 
of knockdown over knockout, the confounding issue of offtarget effects need to be addressed before deployment of the ribozyme approach in solventogenic Clostridium species. Such concerns may be partly offset as long as the defined payoffs are accomplished as illustrated here for solventogenesis. Regardless, the M1GS ribozyme approach could be harnessed to uncover new determinants of phenotypes such as growth, solventogenesis, and sporulation, and inspire targeted genetic manipulations to boost $\mathrm{ABE}$ production. Indeed, this work shows that MIGS technology has the potential of being a metabolic engineering tool of solventogenic Clostridium species, and perhaps, other microorganisms. The recent demonstration of the utility of the endogenous type IB CRISPR-Cas machinery as a powerful tool for engineering solventogenic Clostridium species (Payne et al., 2016; Zhang et al., 2018; Atmadjaja et al., 2019) further highlights the potential for using the RNase P-based approach as a geneknockdown complement to a knockout method.

\section{DATA AVAILABILITY STATEMENT}

The original contributions presented in the study are included in the article/Supplementary Material, further inquiries can be directed to the corresponding author/s.

\section{AUTHOR CONTRIBUTIONS}

TE and VG conceived and designed the study. VU, LL, and CO performed the experiments. VU analyzed the data. VU and LL

\section{REFERENCES}

Altman, S. (2007). A view of RNase P. Mol. Biosyst. 3, 604-607. doi: 10.1039/ b707850c

Atmadjaja, A. N., Holby, V., Harding, A. J., Krabben, P., Smith, H. K., and Jenkinson, E. R. (2019). CRISPR-Cas, a highly effective tool for genome editing in Clostridium saccharoperbutylacetonicum N1-4(HMT). FEMS Microbiol. Lett. 366:fnz059. doi: 10.1093/femsle/fnz059

Bai, Y., Gong, H., Li, H., Vu, G. P., Lu, S., and Liu, F. (2011). Oral delivery of RNase P ribozymes by Salmonella inhibits viral infection in mice. Proc. Natl. Acad. Sci. U.S.A. 108, 3222-3227. doi: 10.1073/pnas.1014975108

Bai, Y., Rider, P. J., and Liu, F. (2010). Catalytic M1GS RNA as an antiviral agent in animals. Methods Mol. Biol. 629, 339-353.

Bejerano-Sagie, M., Oppenheimer-Shaanan, Y., Berlatzky, I., Rouvinski, A., Meyerovich, M., and Ben-Yehuda, S. (2006). A checkpoint protein that scans the chromosome for damage at the start of sporulation in Bacillus subtilis. Cell 125, 679-690. doi: 10.1016/j.cell.2006.03.039

Cobaleda, C., and Sánchez-García, I. (2000). In vivo inhibition by a site-specific catalytic RNA subunit of RNase P designed against the BCR-ABL oncogenic products: a novel approach for cancer treatment. Blood 95, 731-737. doi: 10.1182/blood.v95.3.731.003k28_731_737

Corrigan, R. M., and Gründling, A. (2013). Cyclic di-AMP: another second messenger enters the fray. Nat. Rev. Microbiol. 11, 513-524. doi: 10.1038/ nrmicro3069

Devonshire, A. S., Sanders, R., Whale, A. S., Nixon, G. J., Cowen, S., Ellison, S. L. R., et al. (2016). An international comparability study on quantification of mRNA gene expression ratios: CCQM-P103.1. Biomol. Detect. Quantif. 8, $12-28$.

Ezeji, T. C., Groberg, M., Qureshi, N., and Blaschek, H. P. (2003). Continuous production of butanol from starch-based packing peanuts. Appl. Biochem. Biotechnol. 108, 375-382. doi: 10.1385/abab:106:1-3:375 wrote the first draft of the manuscript. All authors contributed to the writing of the final draft and approved the submitted version.

\section{FUNDING}

Funding for this research was provided in part by the USDA NIFA Hatch grant (Project No. OHO01333), National Science Foundation Cellular \& Biochemical Engineering program (Award Number: 1803022), by state funds allocated to the Ohio Agricultural Research and Development Center (OARDC, OHOA1682), and the Behrman Research Fund (to VG).

\section{ACKNOWLEDGMENTS}

We thank Dr. Wouter Kuit (Wageningen University and Research Centre, Wageningen, Netherlands) for kindly providing us pWUR459 and pWUR460 expression plasmids.

\section{SUPPLEMENTARY MATERIAL}

The Supplementary Material for this article can be found online at: https://www.frontiersin.org/articles/10.3389/fbioe. 2021.669462/full\#supplementary-material

Ezeji, T. C., Milne, C., Price, N. D., and Blaschek, H. P. (2010). Achievements and perspectives to overcome the poor solvent resistance in acetone and butanolproducing microorganisms. Appl. Microbiol. Biotechnol. 85, 1697-1712. doi: 10.1007/s00253-009-2390-0

Ezeji, T. C., Qureshi, N., and Blaschek, H. P. (2007). Butanol production from agricultural residues: impact of degradation products on Clostridium beijerinckii growth and butanol fermentation. Biotechnol. Bioeng. 97, 14601469. doi: 10.1002/bit.21373

Forster, A. C., and Altman, S. (1990). External guide sequence for an RNA enzyme. Science 249, 783-786. doi: 10.1126/science.1697102

Gopalan, V., Vioque, A., and Altman, S. (2002). RNase P: variations and uses. J. Biol. Chem. 277, 6759-6762. doi: 10.1074/jbc.r100067200

Grupe, H., and Gottschalk, G. (1992). Physiological events in Clostridium acetobutylicum during the shift from acidogenesis to solventogenesis in continuous culture and presentation of a model for shift induction. Appl. Environ. Microbiol. 58, 3896-3902. doi: 10.1128/aem.58.12.3896-3902.1992

Guerrier-Takada, C., and Altman, S. (2000). Inactivation of gene expression using ribonuclease P and external guide sequences. Methods Enzymol. 313, 442-456. doi: 10.1016/s0076-6879(00)13028-9

Hall, B. G., Pikis, A., and Thompson, J. (2009). Evolution and biochemistry of family 4 glycosidases: implications for assigning enzyme function in sequence annotations. Mol. Biol. Evol. 26, 2487-2497. doi: 10.1093/molbev/msp162

Ho, N. W., Chen, Z., and Brainard, A. P. (1998). Genetically engineered Saccharomyces yeast capable of effective cofermentation of glucose and xylose. Appl. Environ. Microbiol. 64, 1852-1859. doi: 10.1128/aem.64.5.1852-1859. 1998

Jones, D. T., and Woods, D. R. (1986). Acetone-butanol fermentation revisited. Microbiol. Rev. 50, 484-524. doi: 10.1128/mr.50.4.484-524.1986

Khvorova, A., Lescoute, A., Westhof, E., and Jayasena, S. D. (2003). Sequence elements outside the hammerhead ribozyme catalytic core enable intracellular activity. Nat. Struct. Biol. 10, 708-712. doi: 10.1038/nsb959 
Kim, A. Y., and Blaschek, H. P. (1993). Construction and characterization of a phage-plasmid hybrid (phagemid), pCAK1, containing the replicative form of virus-like particle CAKi isolated from Clostridium acetobutylicum NCIB 64444. J. Bacteriol. 175, 3838-3842. doi: 10.1128/jb.175.12.3838-3843.1993

Lai, L. B., Vioque, A., Kirsebom, L. A., and Gopalan, V. (2010). Unexpected diversity of RNase P, an ancient tRNA processing enzyme: challenges and prospects. FEBS Lett. 584, 287-296. doi: 10.1016/j.febslet.2009.11.048

Leboeuf, C., Leblanc, L., Auffray, Y., and Hartke, A. (2000). Characterization of the CcpA gene of Enterococcus faecalis: identification of starvation-inducible proteins regulated by CcpA. J. Bacteriol. 182, 5799-5806. doi: 10.1128/jb.182. 20.5799-5806.2000

Li, Y., and Altman, S. (1996). Cleavage by RNase P of gene N mRNA reduces bacteriophage lambda burst size. Nucleic Acids Res. 24, 835-842. doi: 10.1093/ nar/24.5.835

Liu, F. (2010). "Ribonuclease P as a tool," in Ribonuclease P, eds F. Liu and S. Altman (New York: Springer), 153-172.

Liu, F., and Altman, S. (1995). Inhibition of viral gene expression by the catalytic RNA subunit of RNase P from Escherichia coli. Genes Dev. 9, 471-480. doi: 10.1101/gad.9.4.471

Ludwig, H., Meinken, C., Martin, A., and Stulke, J. (2002). Insufficient expression of the ilv-leu operon encoding enzymes and branched-chain amino acid biosynthesis limits growth of Bacillus subtilis CcpA mutant. J. Bacteriol. 184, 5174-5178. doi: 10.1128/jb.184.18.5174-5178.2002

Lundblad, E. W., Xiao, G., Ko, J. H., and Altman, S. (2008). Rapid selection of accessible and cleavable sites in RNA by Escherichia coli RNase P and random external guide sequences. Proc. Natl. Acad. Sci. U.S.A. 105, 2354-2357. doi: 10.1073/pnas.0711977105

Mazzeo, M. F., Cacace, G., Peluso, A., Zotta, T., Muscariello, L., Vastano, V., et al. (2012). Effect of inactivation of CcpA and aerobic growth in Lactobacillus plantarum: A proteomic perspective. J. Proteomics 75, 4050-4061. doi: 10.1016/ j.jprot.2012.05.019

Mehne, F. M. P., Gunka, K., Eilers, H., Herzberg, C., Kaever, V., and Stülke, J. (2013). Cyclic di-AMP homeostasis in Bacillus subtilis: both lack and high level accumulation of the nucleotide are detrimental for cell growth. J. Biol. Chem. 288, 2004-2017. doi: 10.1074/jbc.m112.395491

Mitchell, W. J. (1998). Physiology of carbohydrate to solvent conversion by clostridia. Adv. Microb. Physiol. 39, 31-130. doi: 10.1016/s0065-2911(08) 60015-6

Oppenheimer-Shaanan, Y., Wexeselblatt, E., Katzhendler, J., Yavin, E., and BenYehuda, S. (2011). c-di-AMP reports DNA integrity during sporulation in Bacillus subtilis. EMBO Rep. 12, 594-601. doi: 10.1038/embor.2011.77

Ounine, K., Petitdemange, H., Raval, G., and Gay, G. (1985). Regulation and butanol inhibition of $\mathrm{D}$-xylose and $\mathrm{D}$-glucose uptake in Clostridium acetobutylicum. Appl. Environ. Microbiol. 49, 874-878. doi: 10.1128/aem.49.4. 874-878.1985

Payne, M. E., Bruder, M. R., Moo-Young, M., Chung, D. A., and Chou, C. P. (2016). Harnessing heterologous and endogenous CRISPR-Cas machineries for efficient markerless genome editing in Clostridium. Sci. Rep. 6:25666.

Przybilski, R., Gräf, S., Lescoute, A., Nellen, W., Westhof, E., Steger, G., et al. (2005). Functional hammerhead ribozymes naturally encoded in the genome of Arabidopsis thaliana. Plant Cell 17, 1877-1885. doi: 10.1105/tpc.105.03 2730

Ren, C., Gu, Y., Hu, S., Wu, Y., Wang, P., Yang, Y., et al. (2010). Identification and inactivation of pleiotropic regulator CcpA to eliminate glucose repression of xylose utilization in Clostridium acetobutylicum. Metab. Eng. 12, 446-454. doi: 10.1016/j.ymben.2010.05.002

Ren, C., Gu, Y., Wu, Y., Zhang, W., Yang, C., Yang, S., et al. (2012). Pleiotropic functions of catabolite control protein CcpA in butanol-producing Clostridium acetobutylicum. BMC Genomics 13:349. doi: 10.1186/1471-2164-13-349

Scott, C. W., and Engelke, D. R. (2006). Ribonuclease P: the evolution of an ancient RNA enzyme. Crit. Rev. Biochem. Mol. Biol. 41, 77-102. doi: 10.1080/ 10409230600602634

Shi, Y., Li, Y. X., and Li, Y. Y. (2010). Large number of phosphotransferase gens in the Clostridium beijerinckii NCIMB 8052 genome and study on their evolution. BMC Bioinformatics 11(Suppl. 11):S9.
Siemerink, A. J., Kuit, W., López-Contreras, A. M., Eggink, G., van der Oost, J., and Kengen, S. W. M. (2011). D-2,3-butanediol production due to heterologous expression of an acetoin reductase in Clostridium acetobutylicum. Appl. Environ. Microbiol. 77, 2582-2588. doi: 10.1128/aem.01616-10

Singh, K. D., Schmalisch, M. H., Stülke, J., and Görke, B. (2008). Carbon catabolite repression in Bacillus subtilis: quantitative analysis of repression exerted by different carbon sources. J. Bacteriol. 190, 7275-7284. doi: 10.1128/jb.00848-08

Spitale, R. C., Crisalli, P., Flynn, R. A., Torre, E. A., Kool, E. T., and Chang, H. Y. (2013). RNA SHAPE analysis in living cells. Nat. Chem. Biol. 9, 18-20. doi: $10.1038 /$ nchembio.1131

Stülke, J., and Krüger, L. (2020). Cyclic di-AMP signaling in bacteria. Annu. Rev. Microbiol. 74, 159-179. doi: 10.1146/annurev-micro-020518-115943

Sureka, K., Choi, P. H., Precit, M., Delince, M., Pensinger, D. A., Huynh, T. N., et al. (2014). The cyclic dinucleotide c-di-AMP is an allosteric regulator of metabolic enzyme function. Cell 158, 1389-1401. doi: 10.1016/j.cell.2014.07.046

Tsai, H. Y., Lai, L. B., and Gopalan, V. (2002). A modified Bluescript vector for facile cloning and transcription of RNA. Anal. Biochem. 303, 214-217. doi: 10.1006/abio.2001.5567

Uhlenbeck, O. C. (1987). A small catalytic oligoribonucleotide. Nature 328, 596600. doi: $10.1038 / 328596 a 0$

Ujor, V., Agu, C. V., Gopalan, V., and Ezeji, T. C. (2014). Glycerol supplementation enhances furfural detoxification by Clostridium beijerinckii during butanol fermentation. Appl. Microbiol. Biotechnol. 98, 6511-6521. doi: 10.1007/s00253014-5802-8

Vioque, A., Arnez, J., and Altman, S. (1988). Protein-RNA interactions in the RNase P holoenzyme from Escherichia coli. J. Mol. Biol. 202, 835-848. doi: 10.1016/0022-2836(88)90562-1

Watters, K. E., Abott, T. R., and Lucks, J. B. (2016). Simultaneous characterization of cellular RNA structure and function with in-cell SHAPE-Seq. Nucleic Acids Res. 44:e12. doi: 10.1093/nar/gkv879

Whiteley, A. T., Pollock, A. J., and Portnoy, D. A. (2015). The PAMP c-di-AMP is essential for Listeria monocytogenes growth in rich but not minimal media due to a toxic increase in (p)ppGpp. Cell Host Microbe 17, 788-798. doi: 10.1016/j.chom.2015.05.006

Yang, Y., Zhang, H., Lang, N., Zhang, L., Chai, C., He, H., et al. (2020). The small RNA sr8384 is a crucial regulator of cell growth in solventogenic clostridia. Appl. Envi. Microbiol. 86:e00665-20.

Zhang, J., Zong, W., Hong, W., Zhang, Z.-T., and Wang, Y. (2018). Exploiting endogenous CRISPR-Cas system for multiplex genome editing in Clostridium tyrobutyricum and engineer the strain for high-level butanol production. Metab. Eng. 47, 49-59. doi: 10.1016/j.ymben.2018.03.007

Zhang, Y., and Ezeji, T. C. (2013). Transcriptional analysis of Clostridium beijerinckii NCIMB 8052 to elucidate the role of furfural stress during acetone butanol fermentation. Biotechnol. Biofuels 6, 66-82. doi: 10.1186/1754-6834-666

Zhao, J., Qian, X., Yeung, P. Y., Zhang, Q. F., and Kwok, C. K. (2019). Mapping in vivo RNA structures and interactions. Trends Biochem. Sci. 44, 555-556. doi: $10.1016 /$ j.tibs.2019.01.012

Zuker, M. (2003). Mfold web server for nucleic acid folding and hybridization prediction. Nucleic Acids Res. 31, 3406-3415. doi: 10.1093/nar/gkg595

Zverlov, V. V., Berezina, O., Velikodvorskaya, G. A., and Schwarz, W. H. (2006). Bacterial acetone and butanol production by industrial fermentation in the Soviet Union: use of hydrolyzed agricultural waste for biorefinery. Appl. Microbiol. Biotechnol. 71, 587-597. doi: 10.1007/s00253-006-0445-z

Conflict of Interest: The authors declare that the research was conducted in the absence of any commercial or financial relationships that could be construed as a potential conflict of interest.

Copyright (c) 2021 Ujor, Lai, Okonkwo, Gopalan and Ezeji. This is an open-access article distributed under the terms of the Creative Commons Attribution License (CC BY). The use, distribution or reproduction in other forums is permitted, provided the original author(s) and the copyright owner(s) are credited and that the original publication in this journal is cited, in accordance with accepted academic practice. No use, distribution or reproduction is permitted which does not comply with these terms. 